\title{
Behavioral Functions of Stimuli Correlated with Transitions between Rich and Lean Schedules of Reinforcement
}

\author{
Cory Whirtley \\ West Virginia University, cwhirtle@mix.wvu.edu
}

Follow this and additional works at: https://researchrepository.wvu.edu/etd

Part of the Experimental Analysis of Behavior Commons

\section{Recommended Citation}

Whirtley, Cory, "Behavioral Functions of Stimuli Correlated with Transitions between Rich and Lean Schedules of Reinforcement" (2020). Graduate Theses, Dissertations, and Problem Reports. 7555. https://researchrepository.wvu.edu/etd/7555

This Dissertation is protected by copyright and/or related rights. It has been brought to you by the The Research Repository @ WVU with permission from the rights-holder(s). You are free to use this Dissertation in any way that is permitted by the copyright and related rights legislation that applies to your use. For other uses you must obtain permission from the rights-holder(s) directly, unless additional rights are indicated by a Creative Commons license in the record and/ or on the work itself. This Dissertation has been accepted for inclusion in WVU Graduate Theses, Dissertations, and Problem Reports collection by an authorized administrator of The Research Repository @ WVU.

For more information, please contact researchrepository@mail.wvu.edu. 
Behavioral Functions of Stimuli Correlated with Transitions between Rich and Lean Schedules of Reinforcement

\author{
Cory Whirtley
}

\author{
Dissertation Submitted \\ to the Eberly College of Arts and Sciences \\ at West Virginia University
}

in partial fulfillment of the requirements for the degree of

Doctor of Philosophy in

Psychology

\author{
Michael Perone, Ph.D., Chair \\ Barry Edelstein, Ph.D. \\ Kennon A. Lattal, Ph.D. \\ Bernard G. Schreurs, Ph.D. \\ Claire C. St. Peter, Ph.D., BCBA-D
}

Department of Psychology

Morgantown, West Virginia

2020

Keywords: transitions, stimulus control, positive reinforcement, escape, observing, pigeons Copyright 2020 Cory Whirtley 


\begin{abstract}
Behavioral Functions of Stimuli Correlated with Transitions between Rich and Lean Schedules of Reinforcement

Cory Whirtley
\end{abstract}

Disruptions in operant behavior in the form of extended pausing reliably occur when there is a discriminable transition from a relatively rich schedule of reinforcement to a relatively lean schedule (i.e., a rich-lean transition). The present experiments assessed the reinforcing and aversive functions of the stimuli correlated with the transitions between rich and lean schedules using observing and escape procedures. In both experiments, pigeons' key pecks were reinforced with food on a compound schedule with two FR components. Completing the FR in the rich component produced a large reinforcer; completing the FR in the lean component produced a small reinforcer. The components alternated semi-randomly to produce four types of transitions: lean-lean, lean-rich, rich-lean, and rich-rich. In the observing experiment (Experiment 1), pigeons responded on a mixed schedule, in which the food key color was not correlated with the transitions. Pecks on a second key, the observing key, converted the mixed schedule to a multiple schedule by changing the food key color to a color correlated with the current transition. Across conditions, the consequences of the observing responses were manipulated by limiting the stimuli that could be produced. The stimuli correlated with the lean-rich and rich-rich transitions maintained observing, indicating that these stimuli were reinforcing. In contrast, the stimuli correlated with lean-lean and rich-lean transitions neither maintained nor punished observing, indicating that these stimuli were neither reinforcing nor aversive. In the escape experiment (Experiment 2), pigeons responded on a multiple schedule. Pecks on a second key, the escape key, darkened the food key, suspended the FR schedule, and changed the stimuli in the chamber. Across conditions, the magnitude of the stimulus changes that occurred following responses on the escape key was manipulated. The magnitude of the stimulus changes had no systematic effect for most of the pigeons; however, escape was more likely to occur during the rich-lean and leanlean transitions than during the lean-rich and rich-rich transitions, indicating that the lean stimuli were aversive. Overall, results from the present experiments indicate that stimuli correlated with lean schedules of reinforcement can acquire aversive functions, but the detection of these functions may depend on the experimental procedure. 


\section{Acknowledgements}

First, I would like to thank Mike Perone for his invaluable guidance during this project and throughout the last several years of graduate school. I will be forever thankful for his contributions to my growth as a researcher, teacher, and professional, as well as his humor, wisdom, and advice about life.

In addition, I would like to thank the other members of my committee, Claire St. Peter, Andy Lattal, Bernie Schreurs, and Barry Edelstein, for their helpful comments and suggestions on my document.

I thank all of my friends and family for their continued support. Special thanks go to Stephanie Jones and Catherine Williams for always helping me see the great parts of graduate school even during the most challenging times. Finally, I am indebted to my fiancé, Forrest Toegel, for helping to carve my path as a behavior analyst and for always providing inspiration and support. 


\section{Table of Contents}

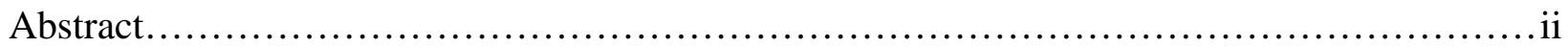

Acknowledgements............................................................ iii

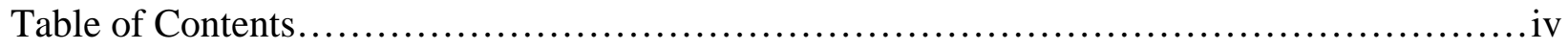

List of Tables.................................................................... vi

List of Figures................................................................. vii

Introduction...................................................................... 1

Statement of the Problem........................................................... 10

General Method.................................................................. 12

Subjects.................................................................. 12

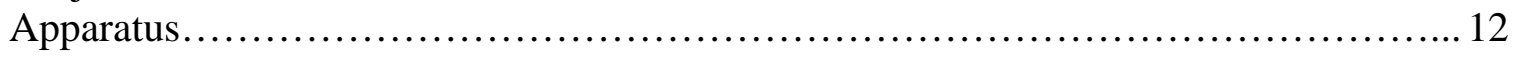

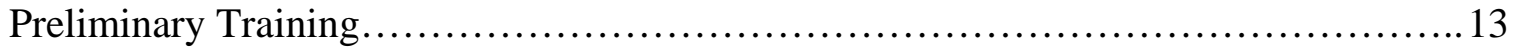

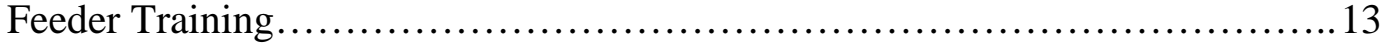

Autoshaping........................................................... 15

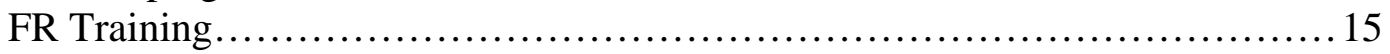

Multiple-schedule Training........................................... 16

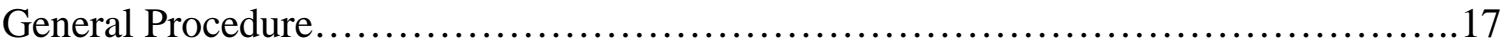

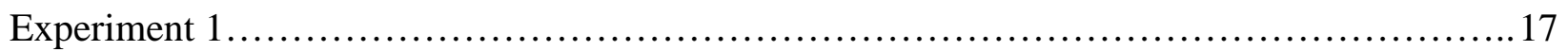

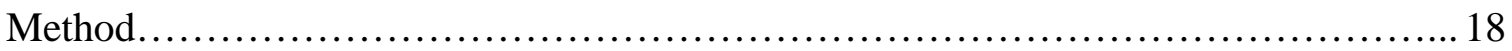

Multiple Schedule.................................................... 18

Acquisition of Observing Behavior....................................... 20

Experimental Conditions................................................ 21

Results.................................................................... 24

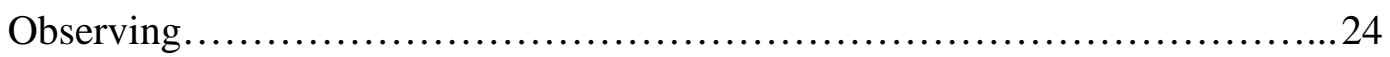

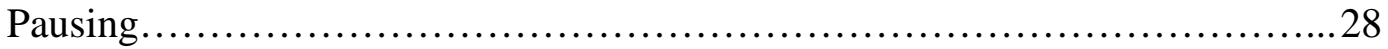

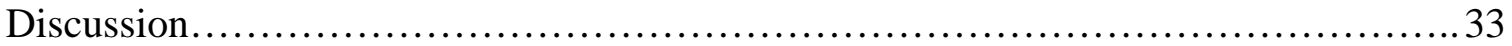

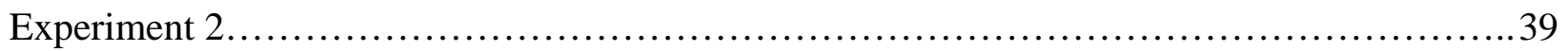

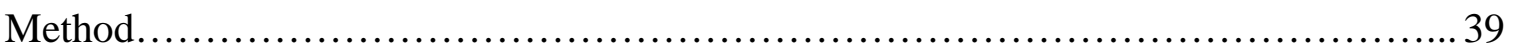

Multiple Schedule.................................................... 39

Escape.............................................................. 41

Experimental Conditions................................................. 44

Results................................................................. 47

Escape............................................................ 47

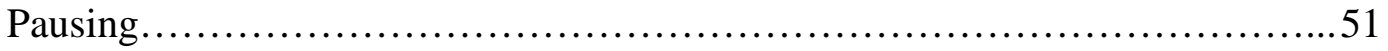

Discussion..................................................................... 55 
Conclusions..................................................................6 60

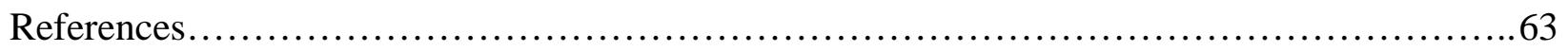

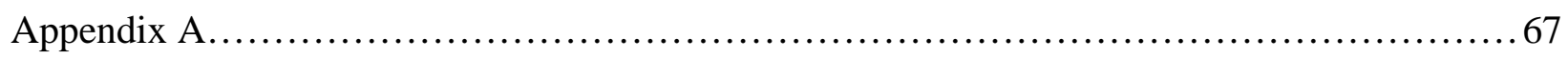

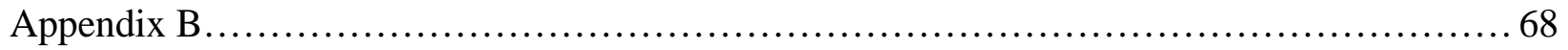

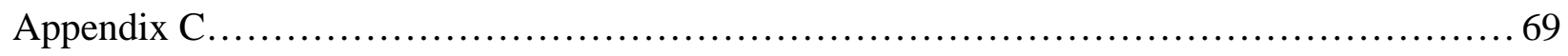

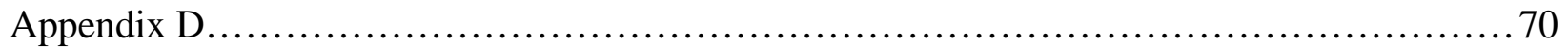

Appendix E..................................................................... 71

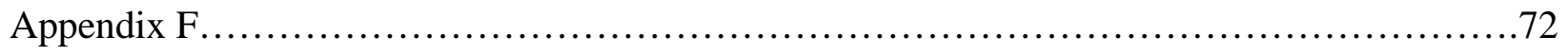

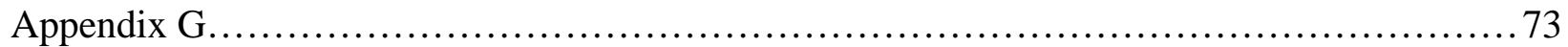

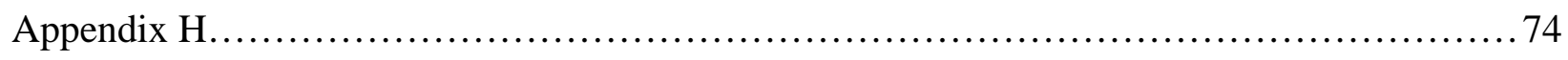




\section{List of Tables}

Table 1. Experiment 1. The terminal fixed-ratio (FR) schedule, reinforcer durations in the lean and rich components, and stimuli presented on each key for each pigeon. The transition types are defined by the past reinforcer, lean $(\mathrm{L})$ or rich $(\mathrm{R})$, followed by the upcoming reinforcer, lean $(\mathrm{L})$ or rich (R). The schedule stimuli for the top two pigeons are defined by the direction, horizontral $(\mathrm{H})$ or vertical (V), and color (Black or White) of the line displayed on the key.

Table 2. Experiment 1. The stimuli (lean-lean (LL), lean-rich (LR), rich-lean (RL), or rich-rich (RR)) that could be produced by a left or right observing (obs) response, the number of each type of transition in which the observing keys were be available, and the number of sessions for each condition. Dashed lines indicate that the observing key was never be activated in that type of transition.

Table 3. Experiment 1. Conditional probability that the mixed stimulus signals an upcoming lean reinforcer across conditions. Probabilities are calculated separately for the different possible presentations of the mixed stimulus: when the left observing key is activated (Left On), when the right observing key is activated (Right On), and when no observing keys are activated (None). The "--" indicates that there were no transitions in which an observing key was not activated.

Table 4. Experiment 2. The terminal fixed-ratio (FR) schedule, reinforcer durations in the lean and rich components, and key colors associated with each transition type for each pigeon. The transition types are defined by the past reinforcer, lean (L) or rich $(\mathrm{R})$, followed by the upcoming reinforcer, lean (L) or rich (R).

Table 5. Experiment 2. The state of session stimuli before an escape response (Pre-Escape), during an escape period (During Escape), and after an escape period is terminated (Post-Escape) for the initial escape procedure and the modified escape procedure.

Table 6. Experiment 2. Conditions (shown in order), degree of line tilt on the escape key during the escape period, the degree of change from the 90-degree line tilt, and the total number of sessions per condition for each pigeon.

Table 7. Experiment 2. Median probability of escape and interquartile ranges for each transition type in the stable sessions for each condition.

Table 8. Experiment 2. Median latency (s) to peck the escape key and interquartile ranges for each transition type in the stable sessions for each condition. Each "--" indicates that either no escape responses occurred or there were not enough escape responses to calculate the interquartile range. 


\section{List of Figures}

Figure 1. The experimental panel of the apparatus. The touchscreen is held to the experimental panel by a metal faceplate. The six circular openings in the metal faceplate permit access to the touchscreen.

Figure 2. Experiment 1. Probability of pecking the left and right observing keys. The conditions, shown in the labels above each phase, differed in the stimuli produced by pecking each key: all four stimuli (ALL), lean-rich (LR), rich-rich (RR), lean-lean (LL), or rich-lean (RL).

Figure 3. Experiment 1. Latencies (s) to peck the left and right observing keys. The conditions, shown in the labels above each phase, differed in the stimuli produced by pecking each key: all four stimuli (ALL), lean-rich (LR), rich-rich (RR), lean-lean (LL), or rich-lean (RL). Data points are missing for some sessions in conditions 3, 4, and 5 Pigeons 12749, 12777, and 15390 because no observing responses occurred during these sessions.

Figure 4. Experiment 1. Percent of total time spent pausing in each of the four transitions, leanlean (LL), lean-rich (LR), rich-lean (RL), and rich-rich (RR), during the multiple schedule training (leftmost column), conditions 1 and 2 combined, and conditions 3, 4, and 5 combined. Percent of total time spent pausing was calculated separately for the transitions that occurred in the presence of the schedule stimuli and in the presence of the mixed stimulus.

Figure 5. Experiment 2. The eight types of transitions between the past and upcoming rich and lean reinforcers. Escape was available in half of each type of transition.

Figure 6. Experiment 2. Median probability of escape (left column) and total time spent in escape (right column) as a function of the line tilt on the escape key. The data paths are defined by transition type: lean-lean (LL), lean-rich (LR), rich-lean (RL), and rich-rich (RR).

Figure 7. Experiment 2. Percent of total spent time pausing during the lean-lean (LL), lean-rich $(\mathrm{LR})$, rich-lean $(\mathrm{RL})$, and rich-rich (RR) transitions during the multiple-schedule training (column 1) and during the escape procedure (columns 2-4). All results are collapsed across the line tilt conditions. The percentages during the escape procedure are shown separately for when no escape key was available (column 2), the escape key was available but was not pecked (column 3), and the escape key was pecked (column 4). Column 4 shows the latencies to peck the escape key, escape durations, and post-escape pauses. All are expressed as the percent of total time spent pausing in each transition. 
Under the right circumstances, schedules of positive reinforcement can evoke disruptions in operant behavior (Perone, 2003). The disruptions of present interest are those observed as pauses in responding on fixed-ratio (FR) schedules, in which reinforcers are delivered following a specific number of responses. Behavioral patterns on FR schedules are characterized by a pause in responding after the delivery of a reinforcer followed by a run of high-rate responding until the delivery of the next reinforcer. Research has shown that these high running response rates are inconsistently related to reinforcement variables (e.g., Ferster \& Skinner, 1957; Mazur, 1983), whereas the pause has been shown to be sensitive (for a review, see Schlinger et al., 2008)

Of particular interest are the pauses that occur when FRs leading to a small reinforcer (a lean FR schedule) are juxtaposed with FRs leading to a large reinforcer (a rich FR schedule). Perone and Courtney (1992) trained pigeons to peck a response key on a two-component schedule. In the lean component, completing the FR produced 2-s access to grain; in the rich component, completing the FR produced 6-s access. The lean and rich components alternated in an irregular order to produce four types of transitions between the components: lean-lean, leanrich, rich-lean, and rich-rich. Each type of transition occurred 10 times per session. In some conditions, the rich and lean components were accompanied by different key colors (i.e., a multiple schedule). Pauses were brief except in the rich-lean transition, in which pauses were extended. In other conditions, the components were both accompanied by the same key color (i.e., a mixed schedule). Pauses were short in all of the transitions - that is, the extended pausing in the rich-lean transition no longer occurred. Behavioral disruptions, in the form of pausing, occurred only when transitions from rich to lean components were discriminable.

Extended pausing in discriminable rich-lean transitions has been shown to be a general phenomenon in the laboratory. It has been replicated with rats (Baron et al., 1992; Baron et al., 
1999; Brewer et al., 2017; Galuska \& Yadon, 2011; Sawyer et al., 2019; Wade-Galuska, et al., 2005), pigeons (Langford et al., 2019; Perone \& Courtney, 1992; Retzlaff et al., 2017; Toegel, 2017), hens (Harris et al., 2012; Young et al., 2017), monkeys (Galuska et al., 2007), and humans (Williams et al., 2011). It has been shown to occur when the operational definitions of the rich and lean components are based on reinforcer magnitude (e.g., Perone \& Courtney, 1992), reinforcer delay (e.g., Harris et al., 2012), response requirement (e.g., Baron et al., 1992), and response-force requirement (e.g., Wade-Galuska et al., 2005). In addition, it has been observed when the schedules of reinforcement are FR (e.g., Perone \& Courtney, 1992), fixedinterval (e.g., Carlin, 1998), and progressive-ratio (e.g., Baron et al., 1992), as well as with different types of reinforcers, including food (e.g., Perone \& Courtney, 1992), drugs (e.g., Galuska et al., 2007), and money and tokens (e.g., Williams et al., 2011).

The ubiquity of pausing is especially interesting, in that pausing on ratio schedules is maladaptive: It necessarily extends the amount of time to the next reinforcer. Perone (2003) suggested that pausing may reflect escape from schedule-correlated stimuli. He argued that discriminable shifts in the favorability of the schedule may be aversive and that the pause in responding occurs because the individual is engaging in other behavior to reduce contact with the stimuli. Two primary methods have been used to assess the potential aversive function of these stimuli. In the first, an individual is provided an explicit response option that functions to either reduce or remove the stimuli correlated with the schedule when they are present (an escape procedure). If the escape response is maintained, then the removal of these stimuli is a negative reinforcer. In the second, an individual is provided an explicit response option that functions to produce the stimuli when they are absent (an observing procedure). If the observing response is 
reduced, then the presentation of these stimuli is a punisher. The present experiments adopted these methods. The following sections provide an overview of the research in this area.

Azrin's (1961) study provided early evidence that stimuli correlated with schedules of positive reinforcement can be aversive. Pigeons could respond on two separate keys. Responding on one key, the food key, was reinforced on an FR schedule. A single response on the other key, the escape key, produced a timeout from the schedule: the food key was deactivated so that FR schedule was suspended, the colors of the food and escape keys were changed, and the color and intensity of the houselight were changed. Another response on the escape key reactivated the food key and reinstated the previous stimulus conditions. The pigeons reliably responded on the escape key immediately after the delivery of the reinforcer - the same point in time that pauses occur. These results show that the stimuli associated with the period right after the delivery reinforcers are aversive and that removal of the stimuli is reinforcing.

Zimmerman and Ferster (1964) used a variation of Azrin’s (1961) escape procedure to further assess the removal of schedule stimuli as a reinforcer. Pigeons were trained to peck a red food key on an FR schedule. A single response on an escape key altered the stimulus conditions in the chamber, but did not suspend the FR. After a second peck on the escape key, the stimulus conditions were reinstated. In Phase 1, the escape key was green (different from the food key) and an escape response changed the color on the food key from red to white. In Phase 2, the escape key was red (same as the food key) and an escape response changed both the food and escape keys from red to white. In Phase 3, the procedure was similar to Phase 2, except that an escape response also turned off the houselight. These procedures were designed to produce differing degrees of stimulus change, with the smallest stimulus change occurring in Phase 1 and the largest stimulus change occurring in Phase 3. Presumably, if the stimulus conditions - which 
are all necessarily correlated with the FR schedule - are aversive, a larger stimulus change would function as a stronger reinforcer and maintain higher levels of escape responding. In line with this idea, escape responses occurred at relatively low levels during Phase 1, intermediate levels during Phase 2, and the highest levels during Phase 3. Notably, escape tended to occur immediately after the delivery of the reinforcers. Zimmerman and Ferster's results provide additional evidence that stimuli correlated with the schedule can be aversive, that these stimuli become aversive at the start of the ratio during the pause, and that escape responding can be maintained at higher levels when it results in a greater change in the stimuli.

Cohen and Campagnoni’s (1989) study assessed the removal of schedule stimuli by providing a novel escape response. Pigeons were exposed to fixed-time (FT) or fixed-interval (FI) schedules of food reinforcement. The FT schedules delivered food after a fixed amount of time elapsed, independent of the pigeon's responding; the FI schedules delivered food following a single response after a fixed amount of time elapsed. Across conditions, they measured spatial retreat, that is, the time the pigeon spent in the rear of the chamber. In some of the conditions, spatial retreat was explicitly reinforced by turning off the response-key color and changing the chamber lighting. In these conditions, spatial retreat increased right after the delivery of the reinforcer, indicating that the schedule stimuli were aversive and their removal was reinforcing. In other conditions, when spatial retreat produced no change in the stimulus conditions, the pigeons continued to retreat to the rear of the chamber, but only after the delivery of the food reinforcer - the period in which the schedule is the least favorable because the next reinforcer is the farthest away in time. By retreating to a location away from the schedule stimuli on the response key, the pigeons reduced visual contact with the stimuli. 
Taken together, the results from the studies conducted by Azrin (1961), Zimmerman and Ferster (1964), and Cohen and Campagnoni (1989) show that both pausing and escape responding occur right after the delivery of reinforcers, which suggests that pausing and escape are controlled by common variables. Pigeons will escape during the pause, given the opportunity. This finding is consistent with Perone's (2003) conjecture that pigeons reduce their contact with the schedule stimuli during the pause because the schedule stimuli have become aversive.

Azrin (1961), Zimmerman and Ferster (1964), and Cohen and Campagnoni (1989) all assessed the aversive function of schedule stimuli on simple schedules of reinforcement; however, additional studies have used more complex schedules, such as the mixed and multiple schedules used by Perone and Courtney (1992) describe above. For example, Metzger and Perone (as cited in Perone, 2003) compared both escape and pausing by pigeons in the context of schedules with rich and lean components. Completing the FR schedule produced 2-s access to grain in the lean component and 6-s access in the rich component. The irregular arrangement of the components produced 10 of each type of transition: lean-rich, lean-lean, rich-lean, rich-rich. In half of the transitions of each type, only the food key was available and pauses were measured. In the other half of the transitions, an escape key was activated and lit the same color as the food key at the start of the ratio. If the pigeon pecked the escape key before pecking the food key at the start of the ratio, the stimulus on the food key and the houselight were turned off, the escape key was dimmed, and the food key was deactivated. After another peck on the escape key, all of the original stimuli were reinstated and the food key was reactivated. In the mixedschedule conditions, in which the color of the food key was white for both rich and lean components, pausing was brief in all four transition types and escape rarely occurred. In the multiple-schedule conditions, in which the color of the food key (and escape key) differed in the 
rich and lean components, extended pauses occurred during the rich-lean transitions, and pigeons pecked on the escape key in most of the rich-lean transitions when it was available. These results indicate that both behavioral disruptions, extended pausing and escape from schedule stimuli, occur when transitions from rich and lean components are discriminable.

It is important to note that in Perone and Metzger's study, the escape response removed both the stimuli correlated with the schedule and the schedule itself. It is possible that only the schedule was aversive, and the stimuli served to only identify the schedule component in effect, thereby permitting a discrimination between the various types of schedule transitions. If this were the case, then the differences shown in pausing and escape observed in the mixed and multiple schedules could be attributed to the aversive nature of the transition from the rich to the lean schedule and not the aversive function of the stimuli correlated with the transition.

Everly et al. (2014) designed two experiments to address this possibility. One of the experiments replicated Perone and Metzger's multiple-schedule procedure with one exception: The escape response removed the schedule correlated stimuli, but did not remove the schedule of reinforcement. In half of the transitions of each type, only the food key was available and pauses were measured. In the other half of the transitions, an escape key was available. When the escape key was pecked, the color of the food and escape keys was changed from the multiple-schedule stimulus (red or green) to one uncorrelated with the upcoming reinforcer (white) for the rest of the component. In other words, the escape response changed the multiple schedule to a mixed schedule. The FR schedule on the food key was not suspended and the pigeon could complete the FR in the presence of the mixed stimulus. With this arrangement, pecks on the escape key could be reinforced by a change in the stimulus conditions and not by the removal of the schedule requirements. For all pigeons, the longest pauses occurred during the rich-lean 
transitions. Although the most escape occurred when the upcoming reinforcer was lean, only two of the four pigeons escaped most often during the rich-lean transitions. These results show that escape is controlled by the removal of the stimuli correlated with the schedule requirements even when the schedule requirements are still underway - which indicates that the stimuli are in fact aversive instead of merely discriminative.

Another experiment by Everly et al. (2014) arranged an observing procedure to assess the potential reinforcing and punitive functions of the rich and lean stimuli. Pigeons' pecks on a food key were reinforced on a mixed schedule. In the rich component, completing an FR 100 produced 6- or 7-s access to food. In the lean component, the FR 100 produced 1-s access. In some of the components, one of two observing keys - one on the left and one on the right of the food key - could be lit and activated. When activated, the food and observing keys were always the same color (white) during the mixed schedule. A single peck on an observing key converted the mixed schedule to a multiple schedule by replacing the white color on the two keys with the color associated with the current component (red or green) until the completion of the FR.

Across conditions, the observing keys were activated only in selected transitions. This restricted the multiple-schedule stimuli that could be produced and thereby allowed assessment of the reinforcing or punishing functions of the stimuli. In the baseline condition, both of the observing keys were activated, one at a time, in all four types of transitions: lean-lean, lean-rich, rich-lean, and rich-rich. Therefore, observing on either key could produce the lean or rich stimulus, depending on which type of transition was underway at the time. Pigeons generally pecked the activated observing key at every opportunity.

In another condition, one the observing keys was activated in all transition types and the other observing key was activated only in lean-rich and rich-rich transitions. This arrangement 
limited the consequences of pecking the second observing key to the production of only the rich stimulus. As in baseline, the pigeons generally pecked each of the two observing keys at every opportunity. This result indicates that the rich stimulus was reinforcing because the pigeons would produce it when it was the sole consequence of observing. In addition, occasional production of the lean stimulus on the first observing key did not punish observing below the level of the key that produced only the rich stimulus, indicating that the lean stimulus was not aversive.

In a third condition, one the observing keys was activated in all transition types and the other observing key was activated only in the lean-lean and rich-lean transitions. This arrangement limited the consequences of pecking the second observing key to the production of only the lean stimulus. The pigeons rarely pecked this observing key, indicating that the lean stimulus was not a reinforcer. Everly et al. concluded that the lean stimulus was neither reinforcing nor aversive in this arrangement. This finding is puzzling given that the lean stimulus was aversive enough to engender escape for some of the pigeons in Everly et al.'s (2014) escape experiment.

It is possible that the procedural details of Everly et al.'s (2014) study influenced the aversiveness of the schedule stimuli. Retzlaff et al. (2017) noted two important procedural details. First, the pigeon's escape responding may have been influenced by the fact that the food key and the escape key were always the same color. If the lean stimulus had acquired aversive properties, the pigeons may have been less likely to approach and peck an escape key lit with the stimulus and that this is why Everly et al.'s pigeons failed to escape more frequently. Second, escape responding may have been influenced by limited differentiation of the different types of transitions. Two key colors were used to differentiate the magnitude of the upcoming reinforcer: 
green for the upcoming rich reinforcer and red for the upcoming lean reinforcer. There were no stimuli correlated with the magnitude of the past reinforcer (i.e., the reinforcer just experienced). Therefore, the stimuli correlated with the rich-rich and lean-rich transitions were both green and the stimuli correlated with the lean-lean and rich-lean transitions were both red. The appearance of the same stimulus in lean-lean and rich-lean contexts may have reduced the aversive function of the stimulus correlated with the rich-lean transition by reducing the discriminability between it and the stimulus correlated with the lean-lean transition.

To address these concerns, Retzlaff et al. (2017; Experiment 1) replicated Everly et al.’s (2014) escape experiment with two methodological changes. First, the escape-key stimulus (a black triangle on a white background) was never used on the food key. This was intended to reduce the likelihood that the escape-key color could acquire aversive properties through an association with a transition. Second, a different stimulus (blue, green, red, yellow, or white) was used for each of the four types of transitions. This was intended to increase the discriminability of each of the transitions. An escape response darkened and deactivated the escape key and changed the color of the food key from the multiple-schedule stimulus to one uncorrelated with the upcoming reinforcer for the rest of the component. As in Everly et al.’s (2014) study, pauses were longest in the rich-lean transition for all pigeons and escape occurred the most when the upcoming reinforcer was lean. In addition, seven of the eight pigeons in the study escaped most often in the rich-lean transition. It is possible that this effect was obtained because their procedure successfully increased discriminability among the four transitions, and thereby enhanced the aversiveness of the rich-lean stimulus.

Retzlaff et al. (2017) conducted another experiment in which the escape response removed not only the transition-specific stimuli (as in Experiment 1), but also suspended the FR 
schedule and turned off the houselight. Therefore, an escape response suspended the schedule, darkened the food key, and turned off the houselight. A second peck to the escape key reinstated the schedule and the transition-specific stimuli on the food key, and turned the houselight back on. This procedure modified the Metzger and Perone (as cited in Perone, 2003) escape procedure by using a novel stimulus on the escape key and four colors as transition-specific stimuli. Escape occurred the most when the upcoming reinforcer was lean and four of the six pigeons escaped most often in the rich-lean transitions. In addition, the pauses were the longest in the rich-lean transition for all pigeons.

Overall, Retzlaff et al.’s (2017) study replicated the general finding that stimuli correlated with reinforcement schedules can be aversive, as demonstrated by the maintenance of a response that functioned to remove the stimuli. In addition, their procedural modifications showed that escape responding can become more differentiated between the rich-lean and lean-lean transitions, at least in comparison to the escape responding shown by Everly et al. (2014). In their research, all of the pigeons escaped primarily in the rich-lean and lean-lean transitions; however, only half of the pigeons escaped more in the rich-lean transition than in the lean-lean transition. This suggests that the two transitions may have been difficult to discriminate. Retzlaff et al.'s results are meaningful because they show that when the escape-key stimulus is neutral and the schedule stimuli make the transitions more discriminable, the escape procedure is more likely to detect the aversive functions of the lean stimuli.

\section{Statement of the Problem}

The present experiments were designed to expand upon the line of research investigating conditions under which stimuli correlated with rich and lean schedules are aversive through refinements to the escape and observing procedures described above. In Retzlaff et al.’s (2017) 
experiments, pigeons responded on an escape key to remove stimuli correlated with rich and lean schedules. Throughout both escape experiments, each of the four transition types between rich and lean schedules were correlated with a unique stimulus. They found that most of their pigeons reliably escaped in the rich-lean transition more than any other transition type. It appears that the transition-specific stimuli enhanced the discriminability of the rich-lean transition relative to escape procedures in which the rich-lean and lean-lean transitions are accompanied by the same stimulus (Everly et al., 2014). This enhanced discriminability of the transitions may permit better detection of the aversive functions of lean stimuli.

Everly et al.’s (2014) observing procedure failed to detect any aversive functions of the stimuli associated with the lean schedules. In their procedure, pigeons responded on observing keys to produce stimuli correlated with rich and lean schedules. They found that the production of the lean stimuli did not punish observing responding, which indicated that the lean stimuli were not aversive. The use of transition-specific stimuli may enhance the ability of the observing procedure to detect the aversive effects of the schedule stimuli. Experiment 1 evaluated this possibility by replicating Everly et al.'s observing procedure with transition-specific stimuli.

The second experiment was concerned with the magnitude of the stimulus change that occurs when stimuli correlated with rich and lean schedules can be escaped. Zimmerman and Ferster (1964) provided evidence that the magnitude of stimulus change is an important factor in maintaining escape under simple FR schedules. All of the pigeons in their study pecked an escape key to change the stimuli present in the chamber at the start of each ratio, and escape responses were more likely when the stimulus change was large (the food key and the escape key color changed and the houselight turned off) compared to when it was small (only the food key color changed). These findings should extend to the study of escape on multiple schedules with 
discriminable shifts between rich and lean schedules. Experiment 2 explored systematically altering the physical appearance of the escape key stimulus when an escape response occurred. In addition, the escape procedure included transition-specific stimuli for some of the pigeons to further evaluate this procedural modification.

\section{General Method}

\section{Subjects}

Nine White Carneau pigeons served as subjects. In Experiment 1, all four pigeons (12749, 12777, 9202, and 15390) were experimentally naive. In Experiment 2, three pigeons (12890, 12894, and 15327) were experimentally naive and two pigeons (88 and 90) had prior exposure to FR schedules of reinforcement. All pigeons were maintained at 80 to 85 percent $( \pm 2$ \%) of their free-feeding body weights by delivery of food pellets during sessions and, if necessary, by supplemental feedings at least 30 min after each session. Water was freely available in the home cage, which was kept in a temperature-controlled room with a 12:12 hr light/dark cycle. The treatment of the pigeons was in accordance with National Institutes of Health guidelines and complied with a protocol approved by the West Virginia University Animal Care and Use Committee.

\section{Apparatus}

Sessions were conducted in four sound-attenuating chambers. During sessions, a ventilation fan circulated air and white noise $(80 \mathrm{~dB})$ was played through an 8-ohm speaker to mask extraneous sound. The interior of the chamber area measured $34.3 \mathrm{~cm}$ long, $30 \mathrm{~cm}$ wide, and $37 \mathrm{~cm}$ high. General illumination was provided by a 28-v houselight (No.1820) located on the bottom left corner of the experimental panel. A 7-in ELO AccuTouch ${ }^{\circledR}$ five-wire resistive single-touch touchscreen monitor (model No. 0700L; 800 pixels wide and 480 pixels high; 15.4 
$\mathrm{cm}$ wide and $8.7 \mathrm{~cm}$ tall) was held to the experimental panel by a metal faceplate. The faceplate had six circular openings ( $2.8 \mathrm{~cm}$ in diameter), which allowed access to specific areas of the touchscreen monitor. These openings were arranged in two rows of three spaced evenly $4.2-\mathrm{cm}$ apart from center-to-center. A picture of the touchscreen with the faceplate is shown in Figure 1. The openings became response 'keys' when a color or image was displayed through the opening. The centers of the bottom and top rows of keys were located 23 and $27 \mathrm{~cm}$ above the floor of the chamber, respectively. Only the bottom row of keys (left, center, and right) were used in the present experiments. To create key colors on the touchscreen, the red, green, and blue pixels on the screen were mixed in specific proportions to mimic the colors produced by specific wavelengths of light. These values were based on an RGB-to-nm estimation program (Spectra;

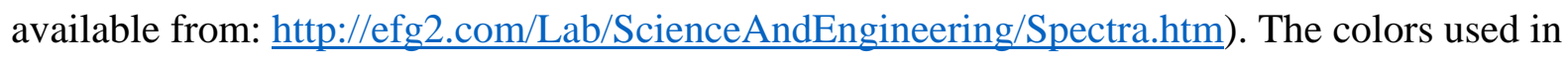
the experiments and the wavelengths that they mimicked are as follows: red $(655 \mathrm{~nm})$, green (500 or $530 \mathrm{~nm}$ ), blue (440 or $460 \mathrm{~nm}$ ), and yellow (590 nm). Visual feedback was provided after each peck on a key by flashing a 15-by-15 pixel gray (Experiment 1) or white (Experiment 2) square in the location of each key peck, and auditory feedback was provided by operating a 28-V relay for $100 \mathrm{~ms}$. Food reinforcers (Purina Mills Nutriblend Green) were delivered through an illuminated (No. 1820 bulb) 5-cm x 6-cm rectangular aperture located approximately $6.7 \mathrm{~cm}$ below the lower edge of the bottom, center key. Pecks were recorded and experimental events were controlled by a computer program written in Visual Basic.

\section{Preliminary Training}

Feeder training. The naive pigeons were trained to eat pellets from the food aperture promptly upon delivery. When the pigeon was placed into the chamber, food was available 


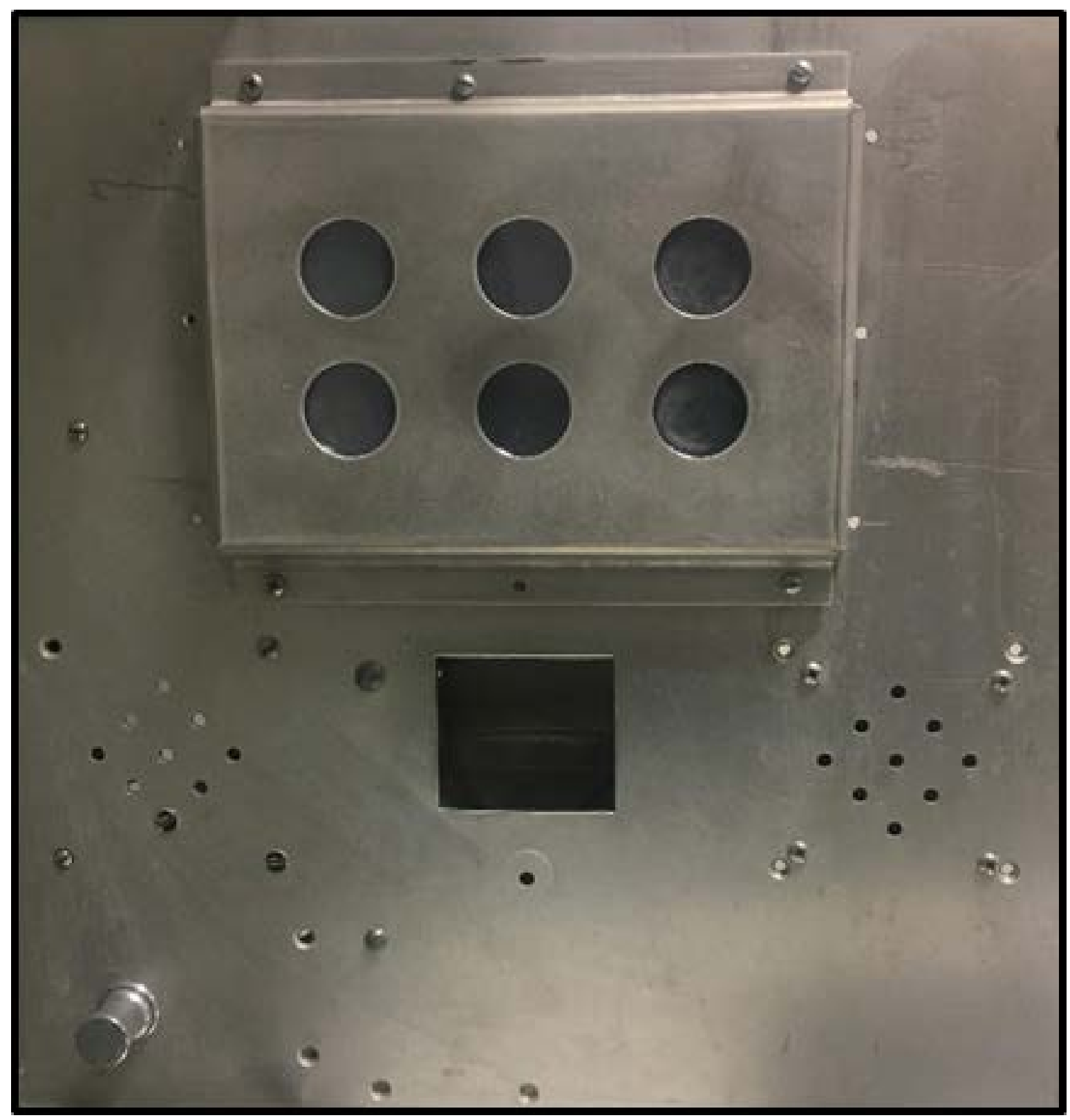

Figure 1. The experimental panel of the apparatus. The touchscreen is held to the experimental panel by a metal faceplate. The six circular openings in the metal faceplate permit access to the touchscreen. 
through the lit aperture until the pigeon ate for $15 \mathrm{~s}$. Thereafter, the 15-s food deliveries occurred at variable intervals with a mean of $15 \mathrm{~s}$. In the next session, the duration of the food deliveries was reduced gradually to $4 \mathrm{~s}$ and the mean interval between deliveries was raised to $60 \mathrm{~s}$. Feeder training was considered complete when the pigeon ate from the food aperture within $2 \mathrm{~s}$ of delivery for five consecutive deliveries.

Autoshaping. For the naive pigeons, an autoshaping procedure was used to establish pecking on the center key. At the beginning of the session, the houselight was turned on and remained on throughout the session except during food deliveries. A trial began by lighting the key yellow. After $8 \mathrm{~s}$, the key was darkened and the food was delivered for $4 \mathrm{~s}$. If the pigeon pecked the key while it was still lit, the key was darkened and the food was delivered immediately. The trials were separated by variable intervals with a mean of $60 \mathrm{~s}$ (range: $45-75$ s). This procedure continued until the pigeon pecked the lit key on 10 consecutive trials or until 160 trials (two sessions) had occurred. Thereafter, the next ten food deliveries were dependent solely on a key peck (FR 1 schedule). Five pigeons successfully completed autoshaping (range: 32-75 trials). The other two pigeons acquired the key peck after one session on the FR 1 schedule.

FR training. The pigeons were trained to respond on the FR schedule in three phases. As in autoshaping, the color of the key was yellow. In Phase 1, pecks on the center key were reinforced on an FR 1 schedule for one session. In Phases 2 and 3, the lit response key was rotated across the three keys, in order from left to right, after every four ratios. This was designed to increase the probability that pigeons would peck the side keys when the escape contingencies (Experiment 1) or the observing contingencies (Experiment 2) were programmed on those keys later. In Phase 2, pecks on the left, center, or right key were reinforced on an FR 1 schedule for at least two sessions. In Phase 3, the FR was raised from 1 to 5 in increments of 1 and from 5 to 25 
in increments of 5. Each ratio value after FR 1 was programmed for a minimum of two sessions, until either the mean running rate on the last session was at least 3 responses per minute higher than that of the last session, or for a maximum of four sessions. During FR training, running rate was calculated by dividing the number of responses after the first peck of the FR by the time between the first and last peck of the FR.

Multiple-schedule training. After each pigeon completed Phase 3 of FR training, the FR was raised in the context of a multiple schedule with two components, each correlated with distinctive colors (described for each experiment below). Identical FR requirements were programmed in each component. The reinforcer durations after the completion of each ratio was changed to create a lean component with 1-s access to food and a rich component with 7-s access.

The rich and lean components alternated in an irregular order. To arrange 40 transitions between components, a computer program generated a sequence of 41 rich and lean components at random, with the following restrictions: (a) the sequence had to include exactly 10 component transitions of each type (lean-lean, lean-rich, rich-lean, and rich-rich) and (b) no more than 3 lean or 3 rich components could be arranged in succession. Any sequence that met these criteria necessarily began and ended with the same type of component.

Across sessions, the response key was rotated, in order from left to right. Two parameters were manipulated until extended pauses were observed reliably in the rich-lean transition: (a) the FR in both components was raised in steps of 5 or 10 responses and (b) the reinforcer durations for the rich and lean components were raised or lowered. When the terminal parameters were reached, the multiple schedule was confined to the center key (food key) for a minimum of 20 
sessions and until pausing in each transition type in the final 10 sessions was stable via visual inspection.

\section{General Procedure}

Sessions were conducted 6 or 7 days per week at approximately the same time each day. After the pigeon was placed into the chamber, a 5-min delay preceded the start of the session to minimize the effects of transportation from the vivarium and handling. During the delay, the touchscreen monitor, chamber lights, and white noise were turned off. At the start of the session, the houselight and the white noise were turned on. During a reinforcer delivery, the houselight and keys were turned off and the food aperture was lit. If the pigeon pecked the screen when no key was present during the first second of the reinforcement cycle, the clock controlling the duration of the reinforcer delivery was reset until pecking ceased for $1 \mathrm{~s}$. Sessions ended after the delivery of 41 reinforcers or after a maximum of $3 \mathrm{hr}$, whichever came first.

\section{EXPERIMENT 1}

The first experiment was designed to replicate Everly et al.’s (2014; Experiment 1) observing procedure with the addition of transition-specific stimuli. In Everly et al.’s observing procedure, pigeons could peck observing keys to change the mixed stimulus on the food key to a stimulus that was correlated with the upcoming reinforcer. The food key stimulus changed to green when the upcoming reinforcer was rich and red when it was lean. Therefore, the stimulus correlated with the lean-rich and rich-rich transitions was green and the stimulus correlated with the lean-lean and rich-lean transitions was red. Across conditions, the reinforcing and aversive effects of the rich and lean stimuli were assessed by manipulating which of these stimuli could be produced by an observing response. Everly et al.’s observing procedure did not detect any aversive effects of the lean stimuli; however, this may have occurred because two types of 
transition were correlated with the same key color. Retzlaff et al. (2017) provided evidence that using different stimuli for each of the four transitions (i.e., transition-specific stimuli) enhanced the discriminability of the four transitions. It is possible that by using transition-specific stimuli in Everly et al.'s (2014) observing procedure, the likelihood of detecting aversive effects of the lean stimuli is enhanced by increasing the discriminability of the transitions.

In Experiment 1, pigeons’ food-key responses were reinforced on a multiple schedule with rich and lean FR components to establish extended pausing in the rich-lean transition. As in Retzlaff et al.'s (2017) study, each of the four types of transitions was correlated with a unique stimulus. After extended pausing was established in the rich-lean transitions, transition-specific stimuli were replaced with a single stimulus (mixed stimulus). Pecks on an observing key reinstated the stimulus correlated with the current transition. Across conditions, the observing keys were activated only in selected transitions, which restricted the stimuli that could be produced by observing. The aversive and reinforcing functions of the stimuli were assessed by evaluating the probability and latency of observing.

\section{Method}

Multiple schedule. Throughout the multiple-schedule training, the food key displayed a distinctive stimulus during each of the four types of component transitions (lean-lean, lean-rich, rich-lean, and rich-rich). The four rightmost columns of Table 1 show the stimuli for each type of transition. Initially, the stimuli consisted of variations in the direction (horizontal $[\mathrm{H}]$ or vertical [V]) and color (white or black) of a line that bisected the key. Two pigeons (9202 and 15390) failed to show the typical, extended pause in the rich-lean transition with these stimuli and instead, showed irregular patterns of responding that suggested these pigeons did not discriminate the four stimuli. Therefore, the stimuli for these pigeons were changed to the colors 


\section{Table 1}

Experiment 1. The terminal fixed-ratio (FR) schedule, reinforcer durations in the lean and rich components, and stimuli presented on each key for each pigeon. The transition types are defined by the past reinforcer, lean $(\mathrm{L})$ or rich $(\mathrm{R})$, followed by the upcoming reinforcer, lean (L) or rich (R). The schedule stimuli for the top two pigeons are defined by the direction, horizontral (H) or vertical (V), and color (Black or White) of the line displayed on the key.

\begin{tabular}{|c|c|c|c|c|c|c|c|c|c|}
\hline \multirow[b]{2}{*}{ Pigeon } & \multirow[b]{2}{*}{ FR } & \multicolumn{2}{|c|}{$\begin{array}{c}\text { Reinforcer } \\
\text { Duration (s) }\end{array}$} & \multirow{2}{*}{$\begin{array}{l}\text { Obs Key } \\
\text { Stimulus }\end{array}$} & \multirow{2}{*}{$\begin{array}{c}\text { Mixed } \\
\text { Stimulus } \\
\end{array}$} & \multicolumn{4}{|c|}{ Transition Type } \\
\hline & & Lean & Rich & & & LL & LR & $\mathrm{RL}$ & $\mathrm{RR}$ \\
\hline 12749 & 35 & 1.5 & 5.5 & Blue & Yellow & H Black & V Black & H White & V White \\
\hline 12777 & 75 & 1.5 & 4.5 & Blue & Yellow & H Black & V Black & H White & V White \\
\hline 9202 & 25 & 2.0 & 8.0 & Crosshatch & White & Red & Green & Yellow & Blue \\
\hline 15390 & 60 & 2.0 & 8.0 & Crosshatch & White & Red & Green & Yellow & Blue \\
\hline
\end{tabular}


shown in Table 1. The leftmost columns of Table 1 show the terminal FR and reinforcer durations in the lean and rich components for each pigeon.

Pauses for one pigeon (9202) became so long that it failed to complete the sessions. For this pigeon, the procedure was modified such that sessions would end after 33 (instead of 41) components. This reduced the number of each type of transition from 10 to 8 for this pigeon for the rest of the experiment. After this modification, Pigeon 9202 completed sessions consistently.

Acquisition of observing behavior. After responding stabilized on the multipleschedule, the observing response was introduced. At the start of each component, a mixed schedule was programmed on the food key: The four transition-specific stimuli were withheld and the food key was lit yellow or white, depending on the pigeon (the mixed stimulus; see Table 1). In some components, one of two observing keys - either the one on the left or the one on the right of the food key - was lit and activated. The activated observing key was lit blue or displayed a crosshatch image, depending on the pigeon (see Table 1). A single peck on an activated observing key replaced the mixed schedule stimulus with the stimulus correlated with the current transition until the end of the component.

To establish observing behavior, the observing key was activated only in rich components. This ensured that pecking the observing keys produced only the rich stimuli (i.e., stimuli correlated with lean-rich and rich-rich transitions). These stimuli were presumed to be reinforcers and therefore, pecking the observing keys was likely to be maintained. The active observing key was on the left for a random half of the rich components and on the right for the other half. This procedure allowed for 10 observing responses on the right and 10 observing responses on the left for all pigeons except 9202, whose modified procedure allowed only 8 observing responses on each side. In the other 21 components (17 components for 9202), no 
observing key was activated. To decide which specific components had an active observing key, the following specifications were added to the component sequence criteria: (a) an observing key could not be activated in the first component of a session and (b) an observing key could not be activated in more than two successive components. Sessions continued until at least eight observing responses occurred on each side for two consecutive sessions. Observing behavior was established in four to six sessions for all pigeons.

Experimental conditions. The consequence of pecking the two observing keys was manipulated across experimental conditions by activating the keys only in selected transitions. At the start of each component, the food key was lit with the mixed stimulus. In some components, one of the two observing keys was lit and activated. A single peck on the observing key darkened and deactivated the observing key and replaced the mixed stimulus on the food key with the stimulus correlated with the current transition until the end of the component.

Table 2 shows the experimental conditions, the available stimuli on the food key after a peck on the left or right observing key, the number of transitions with an activated observing key, and the number of sessions for each condition. All pigeons experienced the conditions in the same order. In the baseline condition, an observing key was activated in all 40 transitions, divided equally between the left and right keys. Therefore, the consequences of pecking the two observing keys were equivalent - pecks on either key could produce all four types of stimuli. Observing during the baseline served as the basis of comparison for the subsequent experimental conditions. In conditions 1 through 5, one of the observing keys was activated only in selected transitions. This restricted the stimuli that could be produced, which allowed assessment of the reinforcing and aversive functions of stimuli. 


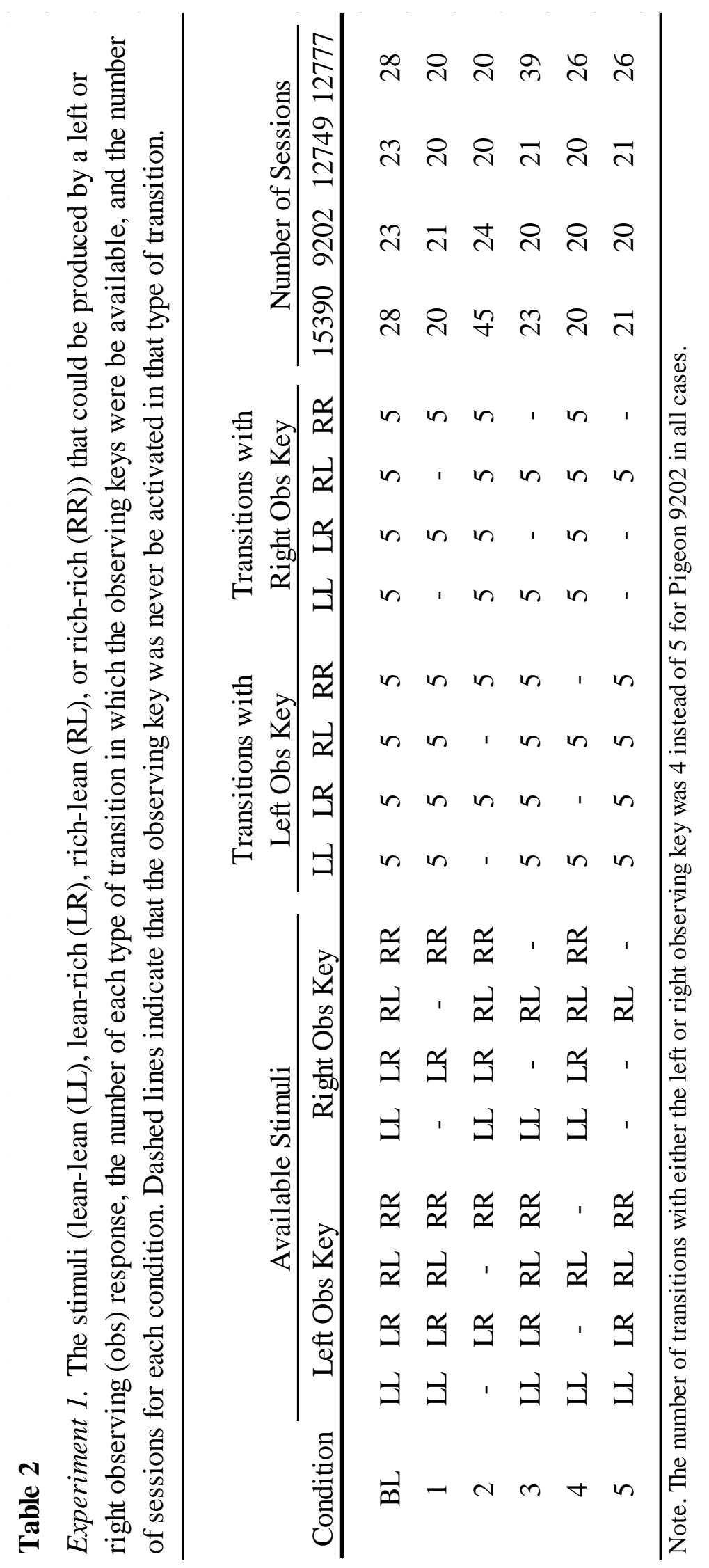


Conditions 1 and 2 were designed to assess the functions of the rich stimuli (i.e., the stimuli correlated with the lean-rich and rich-rich transitions) and the functions of the lean stimuli (i.e., the stimuli correlation with the lean-lean and rich-lean). One of the observing keys was activated only in the lean-rich and rich-rich transitions, which allowed pecks on this key to produce only the two rich stimuli. If these rich stimuli were reinforcing, then pecking this observing key would be maintained. The other observing key was activated in all four transitions, which allowed pecks on this key to produce both the rich stimuli and the lean stimuli (i.e., the stimuli correlated with the lean-lean and rich-lean transitions). If the lean stimuli were aversive, then the likelihood of pecking this key would be lower than pecking the observing key that produced only the rich stimuli.

Conditions 3 and 4 were designed to assess the functions of the lean stimuli. One of the observing keys was activated in all four transitions, which allowed pecks on this key to produce all four types of stimuli. The other observing key was activated only in the lean-lean and richlean transitions, which allowed pecks on this key to produce only the two lean stimuli. If the lean stimuli were reinforcing, then pecking this observing key would be maintained. If the lean stimuli were aversive, then pecking this observing key would not be maintained.

Condition 5 was designed to isolate the reinforcing functions of the rich-lean stimulus. One of the observing keys was activated in all four transition types, which allowed pecks on this key to produce all four types of stimuli. The other observing key was activated only in rich-lean transitions, which allowed pecks on this key to produce only the rich-lean stimulus. If this stimulus was reinforcing, then pecking this observing key would be maintained. If the rich-lean stimulus was aversive, then pecking this observing key would not be maintained. A sixth condition, in which available stimuli programmed in condition 5 would have been switched to 
opposite sides, was planned; however, a pandemic (coronavirus disease 2019 or COVID-19) ended the research.

The stability criteria for each condition was consistent with Everly et al.’s (2014) observing experiment. Each condition lasted a minimum of 20 sessions and continued until the probabilities of left and right observing responses stabilized in each type of transition. When the probabilities showed no increasing or decreasing trend across the last five sessions, responding was judged stable.

\section{Results}

All analyses are based on data from the five stable sessions of each condition.

\section{Observing}

Figure 2 shows the probability of observing in each condition. For each session, probability was calculated by dividing the number of observing responses on the key by the number of times the key was activated.

In the baseline condition when all four of the transition-specific stimuli could be produced by pecking either observing key, the probability of observing was high on both keys for three of the four pigeons. These pigeons pecked each key at almost every opportunity. The remaining pigeon (9202) pecked the left key at almost every opportunity, but was less likely to peck the right key. Because the consequences of the two keys were identical, this result likely reflects a position bias.

The purpose of conditions 1 and 2 was to assess the reinforcing functions of the rich stimuli and the aversive functions of the lean stimuli. When one key could produce the lean and rich stimuli and the other could produce only the two rich stimuli, all pigeons pecked both keys at almost every opportunity. This result shows that the rich stimuli were reinforcing; all pigeons 


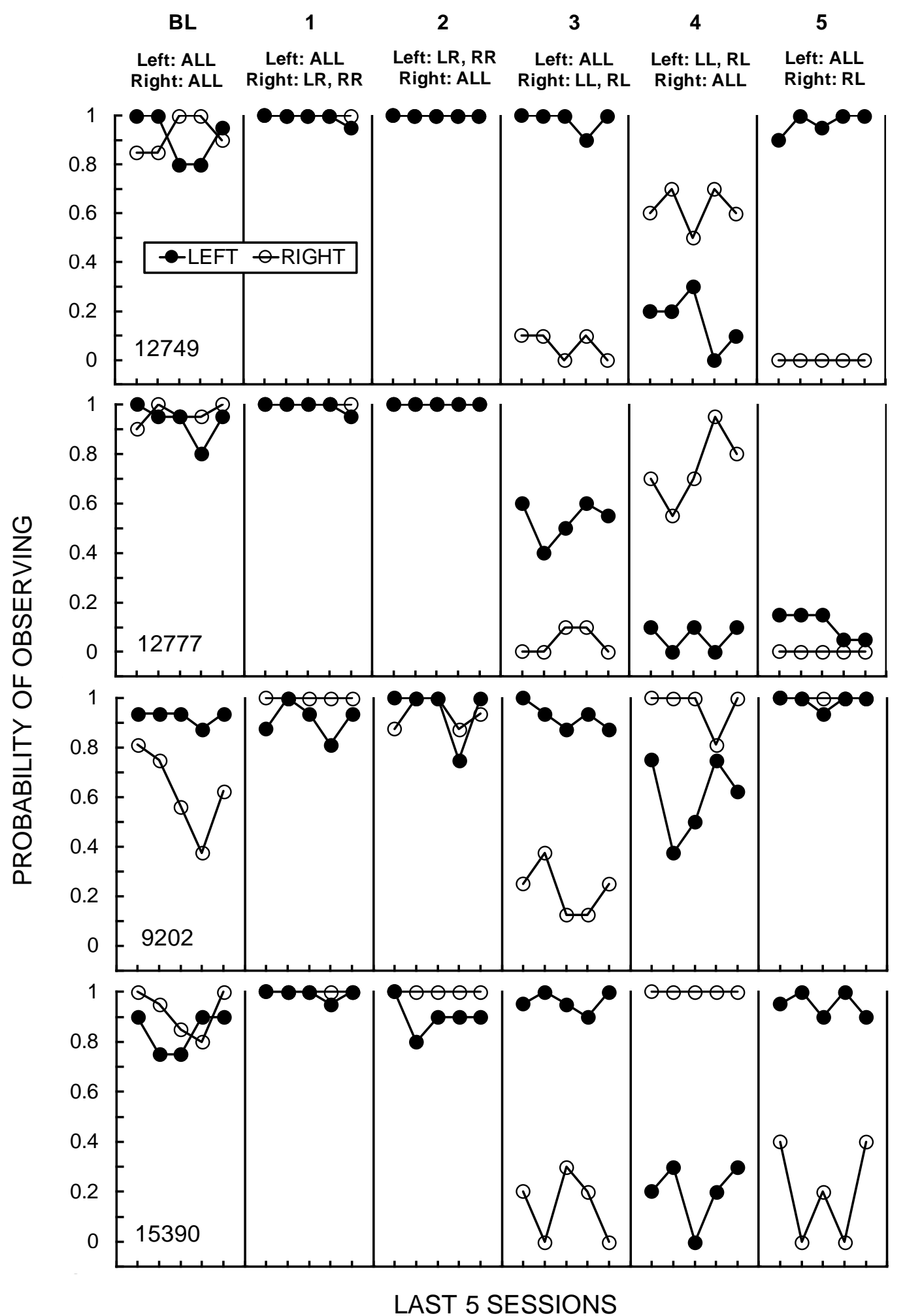

Figure 2. Experiment 1. Probability of pecking the left and right observing keys. The conditions, shown in the labels above each phase, differed in the stimuli produced by pecking each key: all four stimuli (ALL), lean-rich (LR), rich-rich (RR), lean-lean (LL), or rich-lean (RL). 
pecked the key that produced only these two stimuli. There is no evidence that the lean stimuli were aversive. Pigeons continued to peck the observing key that produced the lean stimulus as well as the rich stimuli. If the lean stimuli were aversive, then the probability of pecking the key that produced them should have been lower than the probability on the key that produced only the two rich stimuli.

There are three possible reasons for this result. First, the lean stimuli may have been aversive, but not enough to counteract the reinforcing effects of the rich stimuli that could also be produced by observing. Second, the lean stimuli may have been neutral stimuli and therefore had no effect on observing. If this is the case, then the high probabilities of observing were maintained solely by the production of the rich stimuli. The third possibility is that the lean stimuli were reinforcers, much like the rich stimuli, and therefore, pecking this key was maintained by the production of both rich and lean stimuli.

The purpose of conditions 3 and 4 was to evaluate this third possibility by assessing the possible reinforcing functions of the lean stimuli. When one key could produce all four stimuli and the other could produce only the two lean stimuli, all pigeons were less likely to peck the key that produced only the lean stimuli. Three of the four pigeons $(12749,12777$, and 15390) had probabilities of .3 or less. In some of the stable sessions for these pigeons, this observing key was not pecked at all. Overall, these results suggest that the lean stimuli were not reinforcing pecking the observing key that produced only the two lean stimuli occurred infrequently or not at all.

The purpose of condition 5 was to isolate the reinforcing functions of the rich-lean stimulus. When one key could produce all four stimuli and the other key could produce only the rich-lean stimulus, three of the four pigeons (12749, 9202, and 15390) were much less likely to 
peck the key that produced only the rich-lean stimulus. In fact, two pigeons (12749 and 12777) completely ceased pecking that key at all. Overall, these results suggest that the rich-lean stimulus was not reinforcing - pecking the observing key that produced only the rich-lean stimulus occurred infrequently or not at all.

In conditions 3, 4, and 5, three of the pigeons (12749, 12777, and 15390) did peck the observing key that produced lean stimuli occasionally - though infrequently - and the remaining pigeon (9202) pecked it variably (probabilities ranged from .125 to 1.0), which might suggest that the lean stimuli functioned as weak reinforcers. Although this may be the case, it seems unlikely given that previous research has shown that pigeons will peck a key to escape these lean stimuli (Everly et al., 2014; Retzlaff et al., 2017). Alternatively, the observing response may have been maintained by sensory reinforcement. All observing responses in the present procedures necessarily produced a stimulus change when the mixed stimulus was changed to one of the schedule-correlated stimuli. Previous research has shown that stimulus changes alone can sometimes function as sensory reinforcers (Case \& Fantino, 1981; Kish, 1955, 1966); therefore, sensory reinforcement may explain the occasional pecks on the observing key.

One puzzling result is the occasional low probability of observing on the key that produced all four stimuli for two of the pigeons. For Pigeon 12749, this result occurred in condition 4 (right key; white data points). For Pigeon 12777, this result occurred in condition 3 (left key, black data points), condition 4 (right key, white data points), and condition 5 (left key, black data points). It appears that, in most cases, responding on this key may have failed to recover to high probabilities after it had been reduced to low levels in the previous condition, when it was associated with the production of the lean stimuli. 
Figure 3 shows the median latencies (s) to peck the observing keys in the last 5 sessions of each condition for all pigeons. Latencies provide an additional measure of observing response strength - shorter latencies are indicative of stronger reinforcers and longer latencies are indicative of weaker reinforcers.

Overall, latencies to peck the observing keys were short in the baseline and conditions 1 and 2 when observing responses produced all four stimuli or only rich stimuli. The short latencies in these three conditions correspond with the high probabilities of observing on both keys. When observing probabilities were high and the stimuli were functioning as reinforcers, all pigeons pecked the observing keys quickly.

In conditions 3, 4, and 5, latencies remained short for the observing key that produced all four stimuli, but latencies were longer for the keys that produced only the lean stimuli. The long latencies correspond with the low probabilities of observing on these keys. The one exception to this occurred for Pigeon 9202, whose latencies on these keys were long, despite the fact that the probabilities of observing were sometimes high. It is possible that latency to respond on the observing keys may be a more sensitive measure of response strength than probability of observing. Because response latency is a continuous measure, latencies to peck the observing key can vary across a wide range. In contrast, the probability of observing is limited to the number of times a discrete event occurred or did not occur within a small number of discrete opportunities.

\section{Pausing}

Pausing on the food key was evaluated across each condition and was measured as the time (s) from the start of the component until the fifth peck on the food key. Pausing was calculated separately for the transitions that occurred in the presence of the schedule stimuli and 


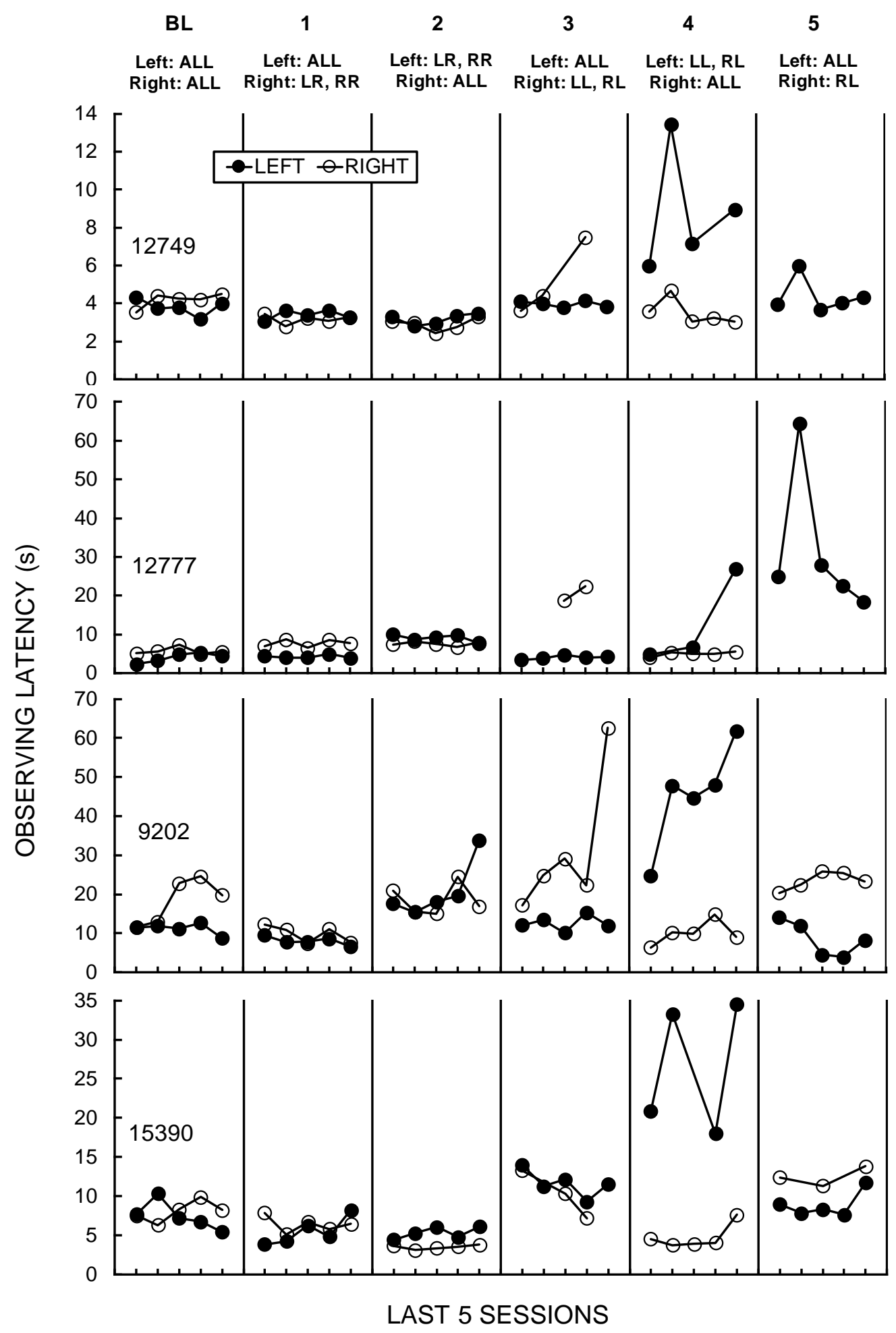

Figure 3. Experiment 1. Latencies (s) to peck the left and right observing keys. The conditions, shown in the labels above each phase, differed in the stimuli produced by pecking each key: all four stimuli (ALL), lean-rich (LR), rich-rich (RR), lean-lean (LL), or rich-lean (RL). Data points are missing for some sessions in conditions 3, 4, and 5 Pigeons 12749, 12777, and 15390 because no observing responses occurred during these sessions. 
in the presence of the mixed stimulus. Figure 4 shows pausing in each of the four transitions relative to the total time spent pausing (i.e., the percentages) during the multiple-schedule training (leftmost column), conditions 1 and 2 combined (middle columns), and conditions 3, 4, and 5 combined (rightmost columns). The percentage for each transition was calculated by dividing the time spent pausing in the transition by the total time spent pausing in all four transitions and multiplying by 100 . Appendix A and B provide the absolute values of the median pauses and interquartile ranges for all individual line-tilt conditions for the multiple-schedule training and the experimental conditions, respectively.

Overall, relative pausing on the food key in the presence of the schedule stimuli (shown with black bars in Figure 4) was the longest during rich-lean transitions followed by intermediate pauses in the lean-lean transitions and short pauses in the lean-rich and rich-rich transitions. These results show that the pattern of pausing, established during the multiple-schedule training, remained under the control of the schedule stimuli when the observing responses produced them in conditions 1 through 5.

Relative pausing on the food key in the presence of the mixed stimulus is shown in the gray bars on Figure 4. The mixed stimulus was present continually during: (a) components in which no observing key was activated and (b) components in which an observing key was active, but not pecked. In conditions 1 and 2, pausing in the presence of the mixed stimulus was similar to pausing in the presence of the schedule stimuli: pauses were longest during rich-lean transitions followed by intermediate pauses in the lean-lean transitions and short pauses in the lean-rich and rich-rich transitions. These results show that the transitions became discriminable in the presence of the mixed stimulus. To help understand how the transitions could have been discriminable, Table 3 shows the conditional probability that the mixed stimulus on the food key 


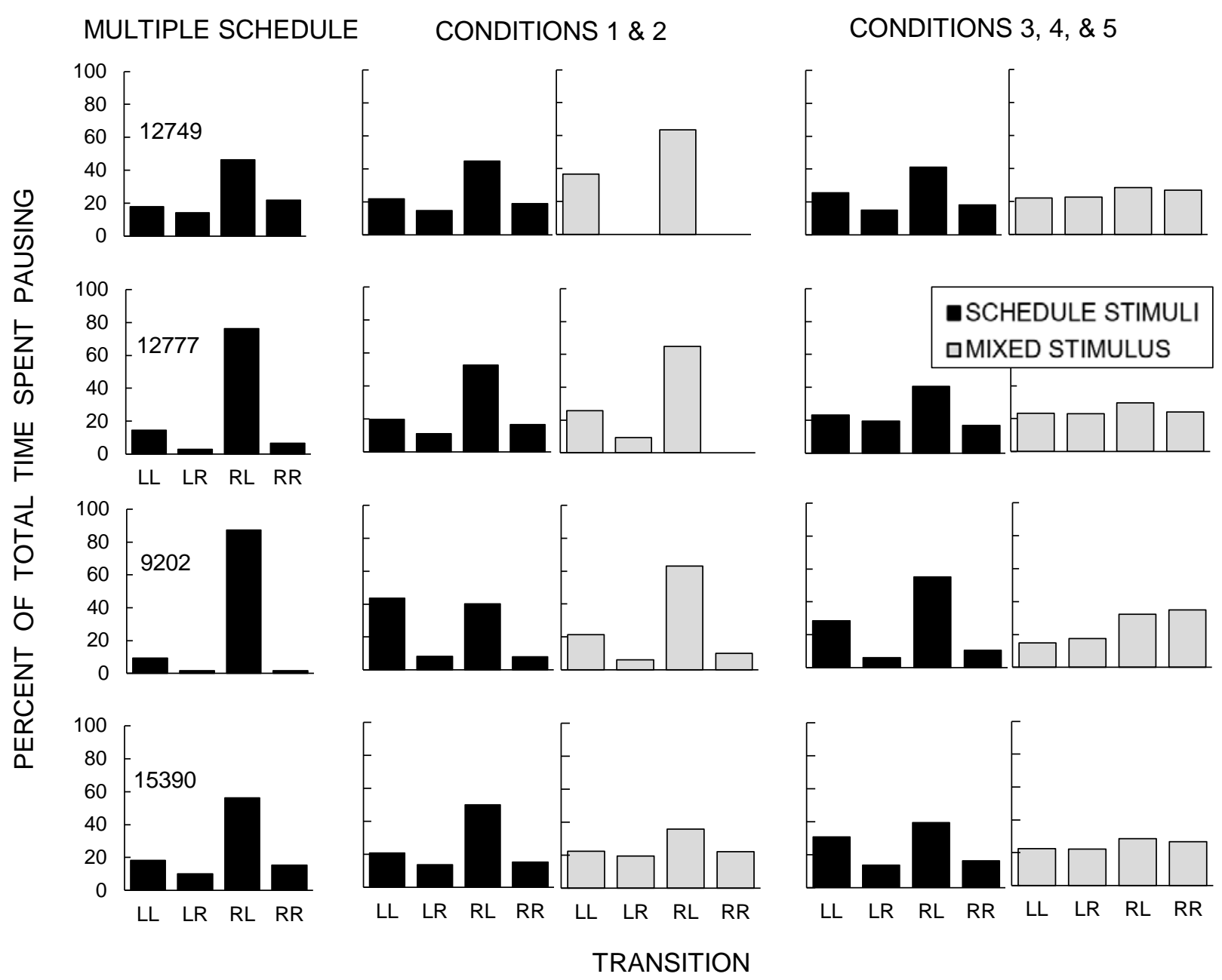

Figure 4. Experiment 1. Percent of total time spent pausing in each of the four transitions, leanlean (LL), lean-rich (LR), rich-lean (RL), and rich-rich (RR), during the multiple schedule training (leftmost column), conditions 1 and 2 combined, and conditions 3, 4, and 5 combined. Percent of total time spent pausing was calculated separately for the transitions that occurred in the presence of the schedule stimuli and in the presence of the mixed stimulus. 


\section{Table 3}

Experiment 1. Conditional probability that the mixed stimulus signals an upcoming lean reinforcer across conditions. Probabilities are calculated separately for the different possible presentations of the mixed stimulus: when the left observing key is activated (Left On), when the right observing key is activated (Right On), and when no observing keys are activated (None). The "--" indicates that there were no transitions in which an observing key was not activated.

\begin{tabular}{cccc}
\hline & \multicolumn{3}{c}{ State of Observing Keys } \\
\cline { 2 - 4 } Condition & Left On & Right On & None \\
\hline BL & .50 & .50 & -- \\
1 & .50 & 0 & 1 \\
2 & 0 & .50 & 1 \\
3 & .50 & 1 & 0 \\
4 & 1 & .50 & 0 \\
5 & .50 & 1 & .33 \\
\hline
\end{tabular}


signaled an upcoming lean reinforcer across all of the conditions. In conditions 1 and 2, the mixed stimulus was fully predictive of an upcoming lean stimulus $(p=1)$ when no observing key was available (None). Because all of the pigeons almost always pecked the observing keys when they were available (and removed the mixed stimulus) in these conditions, pausing in the presence of the mixed stimulus always occurred when no observing key was available, which always signaled that the upcoming reinforcer was lean.

In conditions 3 through 5, pausing in the presence of the mixed stimulus was not differentiated for the four transitions. Instead, pauses were all approximately the same across transitions. This analysis was conducted in the same manner as in conditions 1 and 2, but because the pigeons observed inconsistently, the analysis mixed together pauses that occurred when the mixed stimulus always signaled an upcoming lean reinforcer (e.g., when the right observing key was available in condition $3[\mathrm{p}=1]$ ) and when it did not (e.g., when no observing keys were available in condition $3[\mathrm{p}=0])$. Therefore, it is unclear if the mixed stimulus exerted any control over pausing.

\section{Discussion}

Experiment 1 sought to extend the investigation of the reinforcing and aversive functions of stimuli correlated with rich and lean schedules of reinforcement. The experiment correlated four different stimuli with the four types of transitions that occur when rich and lean schedules of reinforcement alternate irregularly. The functions of these stimuli were assessed by comparing the strength of an observing response across conditions.

First, consider the reinforcing functions of the stimuli. Overall, the rich stimuli (i.e., the stimuli correlated with the lean-rich and rich-rich transitions) functioned as reinforcers and the lean stimuli (i.e., the stimuli correlated with the lean-lean and rich-lean transitions) did not. The 
probability of observing was high when the observing response could produce the rich stimuli and low when it could not. This result shows clearly that the rich stimuli were reinforcing. In contrast, when the observing response could produce only the lean stimuli, the probability of observing was low. This suggests that that the lean stimuli were not reinforcing.

One interpretation is that the lean stimuli were either not reinforcing or they were weak reinforcers, given that some observing responding occurred for all pigeons. It is much more likely that these low levels of observing were maintained by sensory reinforcement. Case and Fantino (1981) demonstrated this possibility by training pigeons to peck a key on a mixed schedule with three components that each had a different FI schedule underway - either FI 20 s, FI 120 s, or FI 180 s. Depending on the condition, an observing response could produce a 10-s presentation of one of the three stimuli correlated with the current schedule. As in the present experiment, observing was either not maintained or maintained at low levels when it could produce only the stimulus correlated with the leanest schedule (FI 180 s). Case and Fantino then exposed pigeons to another condition in which observing responses could produce stimuli that were not correlated with any of the FI schedules. The observing responses occurred either just as often or more often than when the observing responses produced the lean stimuli in the previous conditions. This result shows that pigeons will peck a key, at least at low levels, when the only consequence is a change in sensory stimulation.

Despite the fact that the lean stimuli did not appear to be reinforcing, there was no evidence that the lean stimuli were aversive. Observing probabilities were high when the observing keys produced only rich stimuli and when they produced all four stimuli. If the lean stimuli had been aversive, then the observing probability on the key that produced all four stimuli should have been lower than the probability on the key that produced only rich stimuli. 
That is, the occasional production of the lean stimuli should have punished observing on that key. This did not occur for any pigeon.

Overall, the reinforcing functions of the rich stimuli in the present experiment are consistent with the results in Everly et al.'s (2014) observing experiment. The finding that the lean stimuli were neither reinforcing nor aversive is consistent with Everly et al.'s observing experiment, as well. However, it is inconsistent with the results of studies that used alternative observing procedures. For example, Jwaideh and Mulvaney (1976) used a concurrent observing procedure to assess the functions of the stimuli correlated with rich and lean schedules. In their procedure, two observing keys were always available at the same time. Pecking the food key produced access to grain according to a two-component mixed schedule with a VI 30-s schedule in one component and a VI 120-s schedule in the other. Pecking the observing keys intermittently produced stimuli correlated with the current schedule for $30 \mathrm{~s}$. Therefore, the observing responses could occur freely throughout the components and the rate of observing could be obtained. As in the present experiment, Jwaideh and Mulvaney manipulated the stimuli that could be produced by pecking the two keys. Pecks on one observing key intermittently produced the stimulus associated with the VI 30-s schedule (the rich stimulus) if it was in effect. Pecks on the other observing key intermittently produced the rich stimulus (during the VI 30-s component) and the lean stimulus (during the VI 30-s component). Response rates were lower on the observing key that produced the rich and lean stimuli than on the key that produced only the rich stimuli. Unlike in the present experiment, the production of the lean stimulus punished observing, which showed that the lean stimulus had aversive functions.

One explanation for why the present experiment and Everly et al.'s (2014) observing experiment failed to detect aversive functions of the lean stimuli is that the measures used in 
these experiments were not sensitive enough to detect the aversive functions. The observing keys were available at that start of each ratio and if pecked, were removed for the rest of the ratio. Therefore, pigeons had a limited number of opportunities to peck the observing keys. The measures of response strength were the probability of observing and the latency to peck the observing keys. Because probability of observing is necessarily limited in its range, the latency to peck the observing key, which can vary across a wide range, might serve as a better measure of response strength. In the present experiment, the latency to peck the observing key was long only when the observing response produced lean stimuli, indicating that responding on this key was weak. Although latency may be a more sensitive measure of response strength because it can vary across a wider range than probability, it cannot differentiate between weak reinforcing functions and aversive functions of stimuli as it considers only instances in which the observing key was actually pecked. It is likely that Jwaideh and Mulvaney (1976) were able to detect the aversive function of the lean stimulus because they used a free-operant observing procedure, which did not limit the opportunities to respond on the observing keys. Their procedure permitted an analysis of observing response rates, which could vary across a wide range and detect aversive functions if the response rate is punished by the production of lean stimuli. Thus, the discrepant findings between the present experiment, which did not detect aversive functions of the lean stimuli, and Jwaideh and Mulvaney's experiment, which did, could be explained by the sensitivity of the dependent measures used in each.

It is notable that the present experiment replicated the results of Everly et al.’s (2014) observing procedure despite procedural differences. Whereas Everly et al. used stimuli correlated with the upcoming rich or lean reinforcer, the present experiment used four transition-specific stimuli (i.e., one stimulus for each of the four types of transitions). The purpose of using the four 
transition-specific stimuli in the present experiment was to increase discriminability of the transition type and potentially enhance the aversiveness of the rich-lean transitions such that the aversive effects of stimuli correlated with the rich-lean transitions might be detected in the observing procedure. If the rich-lean stimulus became more aversive, then its production would be more likely to punish the observing responses. Because no punitive effects were found, it is clear that the use of the transition-specific stimuli did not lead to better detection of the aversive effects of the rich-lean stimulus.

This was a surprising result given that the results of Retzlaff et al.'s (2017) procedural changes suggested that the transition-specific stimuli contributed to greater differentiation in escape responding across transitions. The failure of the present procedure to show any additional benefit of the transition-specific stimuli calls into question the contributions of the transitionspecific stimuli in Retzlaff et al.’s experiment. As noted previously, Retzlaff et al. made two procedural changes from Everly et al.’s (2014) escape experiment. One change was the addition of the transition-specific stimuli. The second change was the use of a novel stimulus on the escape key, instead of using the same stimulus as the one displayed on the food key. It is possible that the greater differentiation in escape responding across transitions in Retzlaff et al. can be attributed to this second procedural change alone and not the use of transition-specific stimuli. Therefore, the utility of transition-specific stimuli may be limited.

In light of the present results, it is unclear if the transition-specific stimuli actually enhanced discriminability of the four transitions. Most of the previous studies on transitionrelated disruptions (e.g., Everly et al., 2014; Galuska \& Yadon, 2011; Perone and Courtney, 1992; Toegel, 2017) used two stimuli (e.g., two key colors for pigeons) to differentiate the magnitude of the upcoming rich and lean reinforcers (e.g., green for the upcoming rich reinforcer 
and red for the upcoming lean reinforcer). The stimuli displayed on the food key in these studies were independent of the magnitude of the past reinforcer (i.e., the reinforcer just experienced). Yet, in all of these previous studies, extended pausing was observed only in the rich-lean transition, indicating that responding was influenced by both the delivery of the past reinforcer and the presence of the stimulus correlated with the upcoming reinforcer.

The basis for discriminating the rich-lean transition from the other transitions had two parts: the reinforcer just delivered and the stimulus correlated with the upcoming reinforcer. The impact of the past reinforcer delivery should fade as time elapses. When using transition-specific stimuli, as in the present experiment and in Retzlaff et al.'s (2017) study, the stimuli correlated with both the past and upcoming reinforcers are all unique. Although this added correlation with the past reinforcer is not a necessary condition for the discrimination of the transitions, it allows the discriminative stimuli correlated with the past and upcoming reinforcers to be constantly present. If the constant presence of these stimuli increased the discriminability of the transitions, then it may be possible to mitigate the fading impact of the past reinforcer - at least temporarily.

The present results indicate several lines of future research. To start, it would be informative to evaluate whether transition-specific stimuli enhance the discriminability of transitions across rich and lean schedules. This could be accomplished by replicating the same procedure (e.g., an escape procedure) with and without the transition-specific stimuli within the same animal. The effects of these different stimulus arrangements on an individual animal's pausing, escape, and observing could be assessed, which would provide a direct comparison of the stimulus control exerted in the different stimulus arrangements.

Alternatively, the functions of the transition-specific stimuli could be evaluated using a standard punishment paradigm. For example, pigeons could be trained to respond on a multiple 
schedule with the transition-specific stimuli used in the present experiment. After training, responding would be maintained on a simple schedule in the presence of a neutral, uncorrelated stimulus and some responses would produce the transition-specific stimuli. If any of these stimuli have aversive functions, then responding should be punished when the specific stimuli are presented.

\section{EXPERIMENT 2}

The second experiment was designed to evaluate behavioral effects of the magnitude of the stimulus change that occurs when schedule-correlated stimuli are removed by escape responding. The likelihood of escape may be directly related to the magnitude of stimulus change (Zimmerman \& Ferster, 1964). Key pecks were reinforced on a multiple schedule with rich and lean FR components, each correlated with a specific color, to establish extended pausing in the rich-lean transition. An escape response was made available by activating an escape key. When activated, the escape key was lit white with a black, vertical line (90 degrees) that bisected the key. A peck on the escape key: (a) darkened the food key, (b) suspended the FR schedule, (c) turned off the houselight, and (d) changed the escape-key stimulus. Across conditions, the degree of change in the escape-key stimulus was manipulated by changing the tilt of the line.

\section{Method}

Multiple schedule. Throughout the experiment, distinctive colors on the right key (hereafter, the food key) were correlated with the rich and lean components. The rightmost columns of Table 4 show the color of the key for each of the four types of component transitions (lean-lean [LL], lean-rich [LR], rich-lean [RL], and rich-rich [RR]). For three pigeons (12890, 12894, and 15327), the key color was red or green when the upcoming reinforcer was lean or rich, respectively, independent of the past reinforcer. For two pigeons (88 and 90), the procedure 


\section{Table 4}

Experiment 2. The terminal fixed-ratio (FR) schedule, reinforcer durations in the lean and rich components, and key colors associated with each transition type for each pigeon. The transition types are defined by the past reinforcer, lean (L) or rich (R), followed by the upcoming reinforcer, lean (L) or rich (R).

\begin{tabular}{|c|c|c|c|c|c|c|c|}
\hline \multirow[b]{2}{*}{ Pigeon } & \multirow[b]{2}{*}{ FR } & \multicolumn{2}{|c|}{ Reinforcer Duration (s) } & \multicolumn{4}{|c|}{ Transition Type } \\
\hline & & Lean & Rich & LL & LR & RL & $\mathrm{RR}$ \\
\hline 12890 & 50 & 3.5 & 6.5 & Red & Green & Red & Green \\
\hline 12894 & 75 & 1.5 & 4.5 & Red & Green & Red & Green \\
\hline 15327 & 160 & 1.5 & 7.5 & Red & Gre & Red & reen \\
\hline 88 & 25 & 2.0 & 6.0 & Red & Green & Yellow & Blue \\
\hline 90 & 30 & 3.0 & 7.0 & Red & Green & Yellow & Blue \\
\hline
\end{tabular}


was modified to assess the replicability of the escape results under conditions that were assumed to enhance stimulus control. For these two pigeons, the key colors were transition-specific and therefore the key color in each component depended on the upcoming reinforcer and the past reinforcer. The key was red during the lean-lean transitions, green during lean-rich transitions, yellow during rich-lean transitions, and blue during rich-rich transitions. The leftmost columns of Table 4 show the terminal FR and reinforcer durations in the lean and rich components for each pigeon.

Escape. During the escape procedure, the food key was available at the start of each component and was lit with the multiple-schedule stimulus. The center key (hereafter, the escape key) was activated in half of the components by lighting it white with a black, vertical line $\left(90^{\circ}\right)$ in the middle. A peck on the escape key initiated an escape period. The leftmost columns of Table 5 describe the stimuli before an escape response (Pre-Escape), during an escape period (During Escape), and after an escape period was terminated (Post-Escape) for the initial escape procedure. In the initial version, an escape response: (a) darkened the food key, (b) suspended the FR schedule, and (c) changed the tilt of the line on the escape key. After a minimum of $5 \mathrm{~s}$ in the escape period, a single peck on the escape key: (a) relit the food key, (b) reinstated the FR schedule, and (c) darkened the escape key for the remainder of the component. Using this procedure, only one escape period could be initiated per component.

The initial escape procedure produced two unanticipated results. First, escape occurred infrequently, indicating that the stimulus changes during the escape period were insufficient to maintain the response. Three of the pigeons (12890, 88, and 90) ceased pecking the escape key after a few sessions. The other two pigeons (12894 and 15327) pecked the escape key only once or twice during some of the sessions. Second, on the rare occasion in which an escape response 


\section{Table 5}

Experiment 2. The state of session stimuli before an escape response (Pre-Escape), during an escape period (During Escape), and after an escape period is terminated (Post-Escape) for the initial escape procedure and the modified escape procedure.

\begin{tabular}{|c|c|c|c|c|c|c|}
\hline \multirow[b]{2}{*}{ Source } & \multicolumn{3}{|c|}{ Initial Escape Procedure } & \multicolumn{3}{|c|}{ Modified Escape Procedure } \\
\hline & Pre-Escape & $\begin{array}{l}\text { During } \\
\text { Escape } \\
\end{array}$ & $\begin{array}{c}\text { Post- } \\
\text { Escape } \\
\end{array}$ & Pre-Escape & $\begin{array}{l}\text { During } \\
\text { Escape } \\
\end{array}$ & $\begin{array}{c}\text { Post- } \\
\text { Escape } \\
\end{array}$ \\
\hline Food Key & On & Off & On & On & Off & On \\
\hline FR Schedule & Underway & Suspended & Underway & Underway & Suspended & Underway \\
\hline Escape Key & On $\left(90^{\circ}\right)$ & On $\left(0-180^{\circ}\right)$ & Off & On $\left(90^{\circ}\right)$ & On $\left(0-180^{\circ}\right)$ & Off \\
\hline Houselight & On & On & On & On & Off & On \\
\hline Escape Duration & -- & $\begin{array}{l}\text { Until peck on } \\
\text { escape key }\end{array}$ & -- & -- & $\begin{array}{l}\text { Until peck on } \\
\text { escape key or } \\
2 \text { min }\end{array}$ & -- \\
\hline
\end{tabular}


did occur, the pigeons rarely pecked the escape key a second time to end the escape period. This led to sessions that ended before the completion of 41 components. Because sessions ending after a single escape response would limit contact with the changes in line tilts programmed across conditions, the escape procedure had to be modified.

The rightmost columns of Table 5 describe stimuli during the modified escape procedure. Two important changes were made from the initial procedure. First, the houselight was turned off during the escape periods. This modification was made to increase the overall change in the stimulus conditions of the chamber, which could enhance the reinforcing value of the escape period and increase the salience of the line tilts. Second, a 2-min time limit was added to the duration of the escape period. This modification prevented sessions from ending due to session time-limit requirements after a single escape response. All remaining parts of the procedure were unchanged from the initial escape procedure. Therefore, in the modified escape procedure, an escape response: (a) darkened the food key, (b) suspended the FR schedule (c) changed the tilt of the line on the escape key, and (d) turned off the houselight. After a minimum of $5 \mathrm{~s}$ in the escape period, a single peck on the escape key: (a) relit the food key, (b) reinstated the FR schedule, (c) darkened the escape key, and (d) turned on the houselight for the remainder of the component. After these modifications, all of the pigeons pecked the escape key in every session. Three of the pigeons $(12890,12894$, and 15327) pecked the escape key frequently, whereas the other two pigeons (88 and 90) pecked it approximately one to three times per session.

During the components in which the escape key was activated, the pigeon had to respond on the escape key within the first five pecks of the component or the opportunity to escape during that component was forfeited. The limited availability of the escape key was consistent with previous escape procedures (e.g., Everly et al., 2014) and was based on the finding that 
escape occurs the most often right after the delivery of the reinforcer (e.g., Azrin, 1961). If the first five pecks were on the food key, the escape key was darkened and inoperative for the rest of the component. The fifth peck on the food key, instead of the first peck, was chosen because previous research in our laboratory (Toegel, 2017) showed that some pigeons peck the food key immediately after the delivery of a reinforcer before engaging in the typical, extended pause that characterizes FR responding.

In all sessions, the escape key was activated in half of the lean-rich, lean-lean, rich-lean, and rich-rich transitions. This yielded the eight types of transitions shown in Figure 5. To decide which specific components would activate the escape key, the following specifications were added to the component sequence criteria: (a) the escape key could not be activated in the first component of a session and (b) the escape key could not be activated in more than four successive components.

Experimental conditions. In every experimental condition, the 90-degree line on the escape key was changed immediately after an escape response. Table 6 shows the conditions, degree of line tilt on the escape key during the escape period (with an illustration of the key), the magnitude of the change from the 90-degree line tilt, and the total number of sessions per condition for each pigeon. All pigeons were exposed to the order of conditions shown in the table: $0^{\circ}, 90^{\circ}, 180^{\circ}, 30^{\circ}$, and $150^{\circ}$. In addition, two pigeons (12894 and 90 ) were exposed to the $60^{\circ}$ and $120^{\circ}$ conditions. The $0^{\circ}$ and $180^{\circ}$ line tilts constituted the same visual stimulus, meaning that the third condition was a replication of the first condition for all pigeons.

Each line tilt constituted a different magnitude of stimulus change from the $90^{\circ}$ preescape stimulus. The largest stimulus change ( $90^{\circ}$ change) occurred in the $0^{\circ}$ and $180^{\circ}$ conditions. Intermediate stimulus changes $\left(30^{\circ}\right.$ and $60^{\circ}$ changes) occurred in the $30^{\circ}, 60^{\circ}, 120^{\circ}$, 


\section{Upcoming Reinforcer}

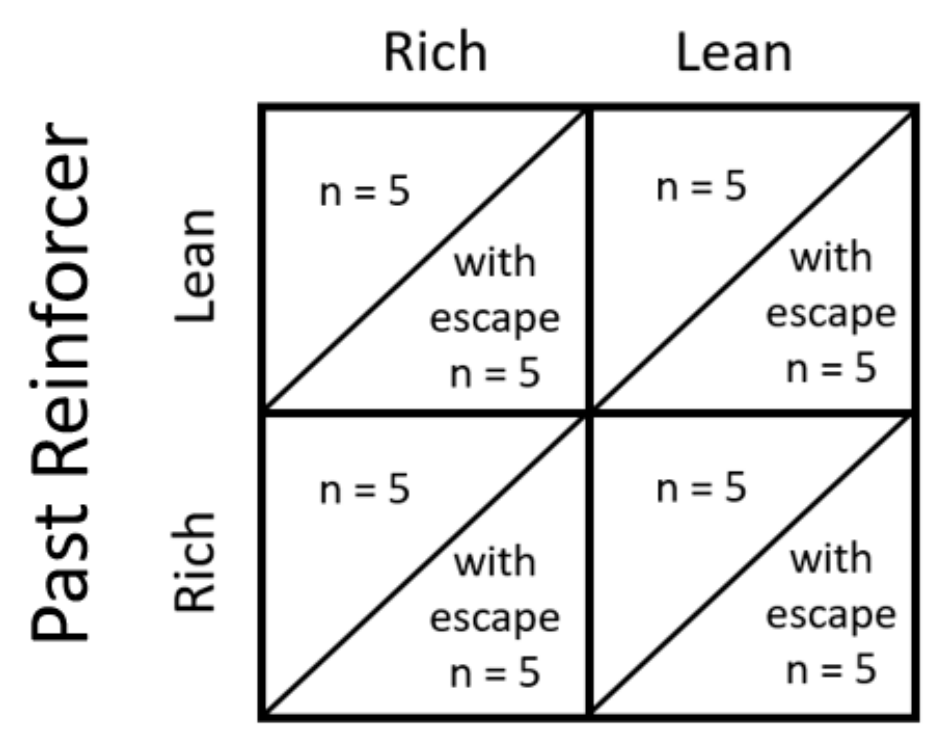

Figure 5. Experiment 2. The eight types of transitions between the past and upcoming rich and lean reinforcers. Escape was available in half of each type of transition. 


\section{Table 6}

Experiment 2. Conditions (shown in order), degree of line tilt on the escape key during the escape period, the degree of change from the 90-degree line tilt, and the total number of sessions per condition for each pigeon.

\begin{tabular}{|c|c|c|c|c|c|c|c|}
\hline \multirow[b]{2}{*}{ Condition } & \multicolumn{2}{|c|}{ Line Tilt $\left(^{\circ}\right)$} & \multicolumn{5}{|c|}{ Pigeons } \\
\hline & During Esc & Change & 12890 & 12894 & 15327 & 88 & 90 \\
\hline 1 & 0 & 90 & 34 & 41 & 47 & 44 & 23 \\
\hline 2 & 90 & 0 & 27 & 20 & 22 & 34 & 20 \\
\hline 3 & 180 & -90 & 21 & 21 & 24 & 12 & 10 \\
\hline 4 & 30 & 60 & 23 & 20 & 20 & 20 & 20 \\
\hline 5 & 150 & -60 & 20 & 22 & 20 & 20 & 20 \\
\hline 6 & 60 & 30 & -- & 20 & -- & -- & 20 \\
\hline 7 & 120 & -30 & -- & 20 & -- & -- & 21 \\
\hline
\end{tabular}

Note: The 0- and 180- degree line tilts are the same stimulus (a horizontal line). Therefore, the third condition for each pigeon consistutes a replication of the first condition. 
and $150^{\circ}$ conditions. The smallest stimulus change $\left(0^{\circ}\right.$ change $)$ occurred in the $90^{\circ}$ condition, in which there was no change to the line tilt displayed on the stimulus key before the escape period. Therefore, the only discriminable stimulus change in this condition was the darkening of the food key and the houselight.

The stability criteria for each condition was consistent with Everly et al.’s (2014) escape experiment. Each condition lasted a minimum of 20 sessions, except for the third condition (the replication), which lasted a minimum of 10 sessions. All conditions ended when probability of escape across the four transition types (lean-rich, lean-lean, rich-lean, and rich-rich) in the last 10 sessions was judged stable by visual inspection.

\section{Results}

The results are expressed in terms of escape responding and pausing as a function of the type of transition between components. Analyses are based on data from the last 10 (stable) sessions of each condition. This normally yielded 200 transitions with the escape key available (4 types of transitions x 5 instances of each transition $\times 10$ sessions) and 200 transitions without the escape key. Some of the pigeons (12890, 88, and 15327) did not complete all of the sessions due to the session time limit and therefore, the number of transitions included in the analysis was lower (see Appendix C for additional details).

\section{Escape}

Each pigeon's escape responding, expressed as the median probability, is shown in the left column of Figure 6. The probability of escape was calculated for each type of transition during every session by dividing the number of escape responses by the number of escape opportunities. Each data point represents the median of the probabilities for one of the four types of transitions from the 10 stable sessions. Table 7 shows the same data with interquartile ranges. 


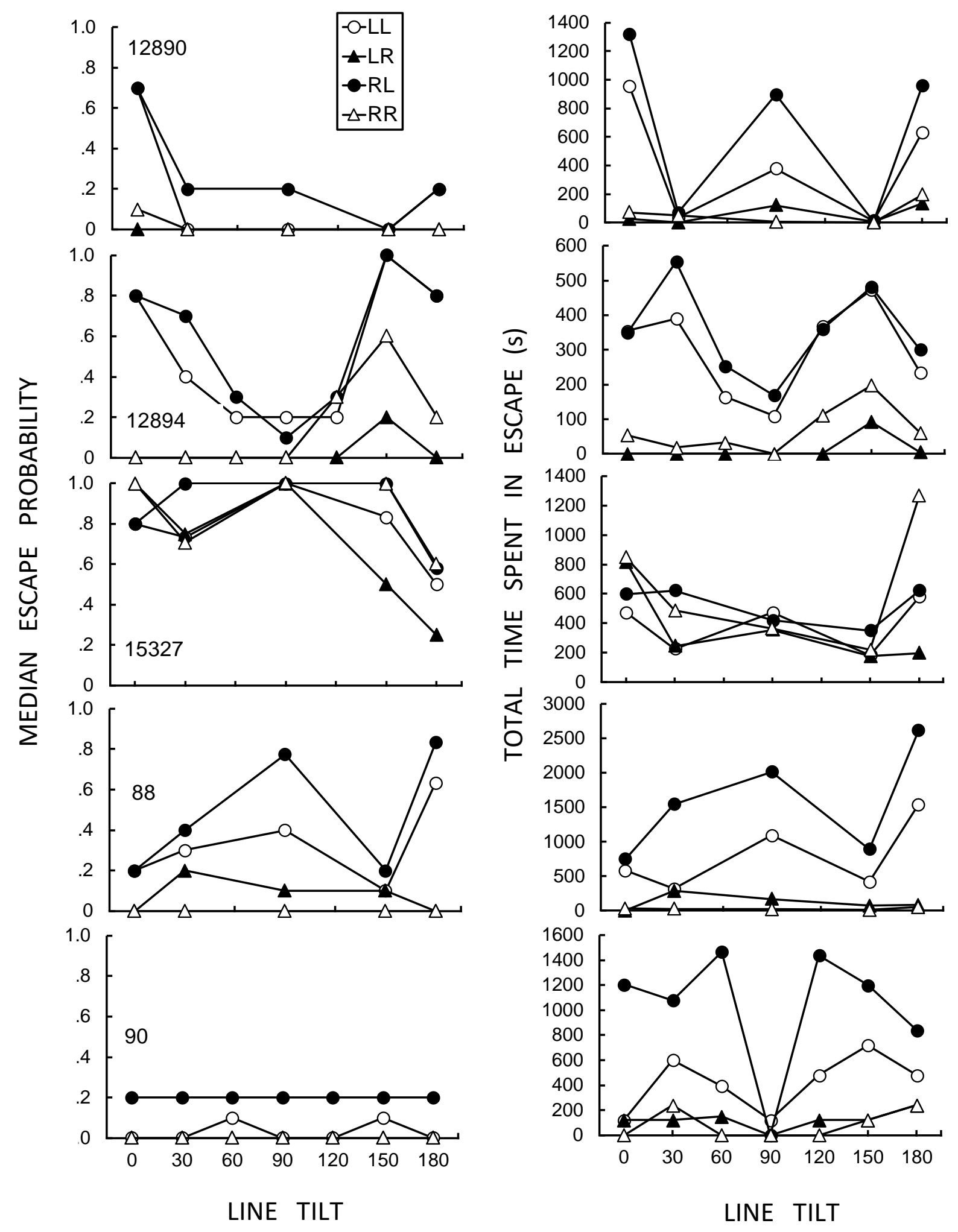

Figure 6. Experiment 2. Median probability of escape (left column) and total time spent in escape (right column) as a function of the line tilt on the escape key. The data paths are defined by transition type: lean-lean (LL), lean-rich (LR), rich-lean (RL), and rich-rich (RR). 
Table 7

Experiment 2. Median probability of escape and interquartile ranges for each transition type in the stable sessions for each condition.

\begin{tabular}{|c|c|c|c|c|c|}
\hline \multirow[b]{2}{*}{ Pigeon } & \multirow{2}{*}{$\begin{array}{c}\text { Line } \\
\text { Tilt } \\
\end{array}$} & \multicolumn{4}{|c|}{ Transition Type } \\
\hline & & Lean-Lean & Lean-Rich & Rich-Lean & Rich-Rich \\
\hline \multirow[t]{5}{*}{12890} & 0 & $.7(.3-.9)$ & $0(0-.2)$ & $.7(.6-1.0)$ & $.1(0-.2)$ \\
\hline & 30 & $0(0-.2)$ & $0(0-0)$ & $.2(0-.2)$ & $0(0-.2)$ \\
\hline & 90 & $0(0-.1)$ & $0(0-0)$ & $.2(0-.3)$ & $0(0-0)$ \\
\hline & 150 & $0(0-0)$ & $0(0-0)$ & $0(0-0)$ & $0(0-0)$ \\
\hline & 180 & $.2(0-.6)$ & $0(0-.3)$ & $.2(.2-.6)$ & $0(0-.3)$ \\
\hline \multirow[t]{7}{*}{12894} & 0 & $.8(.6-.9)$ & $0(0-0)$ & $.8(.6-1.0)$ & $0(0-.3)$ \\
\hline & 30 & $.4(.2-.5)$ & $0(0-0)$ & $.7(.5-.8)$ & $0(0-.2)$ \\
\hline & 60 & $.2(0-.6)$ & $0(0-0)$ & $.3(.2-.5)$ & $0(0-.2)$ \\
\hline & 90 & $.2(.2-.3)$ & $0(0-0)$ & $.1(0-.2)$ & $0(0-0)$ \\
\hline & 120 & $.2(0-.7)$ & $0(0-0)$ & $.3(0-.6)$ & $.3(.2-.5)$ \\
\hline & 150 & $1.0(1.0-1.0)$ & $.2(.2-.6)$ & $1.0(1.0-1.0)$ & $.6(.2-1.0)$ \\
\hline & 180 & $.8(.4-.8)$ & $0(0-0)$ & $.8(.8-1.0)$ & $.2(0-.3)$ \\
\hline \multirow[t]{5}{*}{15327} & 0 & $.8(.6-.9)$ & $1.0(.8-1.0)$ & $.8(.6-.9)$ & $1.0(.8-1.0)$ \\
\hline & 30 & $.7(.3-1.0)$ & $.8(.4-1.0)$ & $1.0(.6-1.0)$ & $.7(.2-1.0)$ \\
\hline & 90 & $1.0(.8-1.0)$ & $1.0(1.0-1.0)$ & $1.0(1.0-1.0)$ & $1.0(1.0-1.0)$ \\
\hline & 150 & $.8(.2-1.0)$ & $.5(.2-.8)$ & $1.0(1.0-1.0)$ & $1.0(.6-1.0)$ \\
\hline & 180 & $.5(.4-.5)$ & $.3(.3-.5)$ & $.6(.5-.8)$ & $.6(.3-.7)$ \\
\hline \multirow[t]{5}{*}{88} & 0 & $.2(0-.3)$ & $0(0-0)$ & $.2(0-.4)$ & $0(0-0)$ \\
\hline & 30 & $.3(0-.6)$ & $.2(0-.3)$ & $.4(.2-.8)$ & $0(0-.1)$ \\
\hline & 90 & $.4(.4-.7)$ & $.1(0-.2)$ & $.8(.6-1.0)$ & $0(0-.2)$ \\
\hline & 150 & $.1(0-.3)$ & $.1(0-.2)$ & $.2(.2-.2)$ & $0(0-0)$ \\
\hline & 180 & $.6(.4-.7)$ & $.1(0-.3)$ & $.8(.5-1.0)$ & $0(0-.2)$ \\
\hline \multirow[t]{7}{*}{90} & 0 & $0(0-0)$ & $0(0-0)$ & $.2(0-.4)$ & $0(0-0)$ \\
\hline & 30 & $0(0-.2)$ & $0(0-0)$ & $.2(0-.2)$ & $0(0-.1)$ \\
\hline & 60 & $.1(0-.2)$ & $0(0-.2)$ & $.2(.2-.5)$ & $0(0-0)$ \\
\hline & 90 & $0(0-0)$ & $0(0-0)$ & $0(0-0)$ & $0(0-0)$ \\
\hline & 120 & $0(0-.2)$ & $0(0-0)$ & $.2(.2-.3)$ & $0(0-0)$ \\
\hline & 150 & $.1(0-.2)$ & $0(0-0)$ & $.2(0-.4)$ & $0(0-0)$ \\
\hline & 180 & $0(0-.2)$ & $0(0-.1)$ & $.2(0-.2)$ & $0(0-.1)$ \\
\hline
\end{tabular}


Across line tilts, escape was more likely to occur in the rich-lean and lean-lean transitions for four of five pigeons (12890, 12894, 88, and 90). Escape in the lean-rich and rich-rich transitions for these four pigeons was rare, with only a few exceptions $\left(120^{\circ}\right.$ and $150^{\circ}$ conditions for 12894). There were no clear systematic patterns of escape across transitions for the fifth pigeon (15327).

Only Pigeon 12894's escape was sensitive to the changes in the degree of the line tilts. In general, probability of escape was directly related to the magnitude of the stimulus change, regardless of the direction of the change. The other four pigeons $(12890,15327,88$ and 90$)$ did not show systematic effects of the line tilts, despite the moderate-to-high probabilities of escape for 88 and 15327. Little can be said about Pigeons 12890 and 90. They rarely escaped, and therefore they likely had insufficient contact with the range of line tilts.

Additional analyses were conducted to determine potential effects of the line tilts on the amount of time spent in escape and the latency to peck the escape key. All of the analyses are limited necessarily to instances in which the escape key was pecked.

The right column of Figure 6 shows the total amount of time spent in escape summed across the 10 stable sessions for each condition. Appendix D shows the same data with numerical accuracy and Appendix E shows the median escape durations. Again, the results for Pigeon 12894 show that, in general, the duration of escape was directly related to the magnitude of stimulus change. This relation corresponds with the effect of the line tilts on the probability of escape shown in the left column of Figure 6. Results of two additional pigeons (15327 and 90) showed some, though limited, evidence that the line tilts had an effect. Results from Pigeon 15327 showed the same general pattern as Pigeon 12894, although the functions were less pronounced. Results for Pigeon 90 appeared to be exclusively sensitive to the difference between 
no change in the line tilt $\left(90^{\circ}\right)$ and some amount of change (all other conditions). Although this pigeon escaped infrequently - about once per session - the escapes generally lasted for the maximum amount of time (120 s) in all of the conditions in which the line tilted to some degree, which led to a longer amount of time spent in escape. This result suggests that this pigeon was sensitive to the presence and absence of a stimulus change on the escape key. Results from the other two pigeons (12890 and 88) showed no systematic effect of line tilt on time spent in escape.

Table 8 shows the median latencies to peck the escape key and interquartile ranges for each transition. Latencies were calculated as the amount of time from the start of a component with an escape key activated to the peck on the escape key. Overall, there was substantial variation in latencies across pigeons, with latencies in the rich-lean and lean-lean transitions tending to be short for Pigeons 12894 and 15327, intermediate for Pigeons 12890 and 90, and long for Pigeon 88. Latencies tended to be short in the lean-rich and rich-rich transitions for all pigeons. Overall, there were no systematic effects of the line tilts on the latency to peck the escape key.

\section{Pausing}

Pausing on the food key was measured as the time from the start of the component until the fifth peck on the food key. Figure 7 shows pausing in each of the four transitions relative to the total time spent pausing (i.e., the percentage). The percentage for each transition was calculated by dividing the time spent pausing in the transition by the total time spent pausing in all four transitions and multiplying by 100.

The leftmost column of Figure 7 (column 1) shows relative pausing for each transition during multiple-schedule training, before the introduction of the escape procedure. Median 
Table 8

Experiment 2. Median latency (s) to peck the escape key and interquartile ranges for each transition type in the stable sessions for each condition. Each "--" indicates that either no escape responses occurred or there were not enough escape responses to calculate the interquartile range.

\begin{tabular}{|c|c|c|c|c|c|}
\hline \multirow[b]{2}{*}{ Pigeon } & \multirow[b]{2}{*}{ Line Tilt } & \multicolumn{4}{|c|}{ Transition Type } \\
\hline & & Lean-Lean & Lean-Rich & Rich-Lean & Rich-Rich \\
\hline \multirow[t]{5}{*}{12890} & 0 & $20.1(9.3-37.7)$ & $4.5(3.5-9.4)$ & 27.5 (16.6-129.6) & $6.4(2.8-13.5)$ \\
\hline & 30 & $194.1(34.2-219.8)$ & -- (--) & $176.5(79.7-273.2)$ & $10.0(7.5-12.0)$ \\
\hline & 90 & 31.3 (16.6-108.2) & $13.7(--)$ & $60.4(28.5-176.7)$ & $4.3(--)$ \\
\hline & 150 & $11.0(--)$ & $1.9(--)$ & $5.2(--)$ & $--(--)$ \\
\hline & 180 & $16.3(6.9-103.0)$ & $9.1(3.0-14.3)$ & $58.9(29.8-160.5)$ & $16.7(8.7-20.4)$ \\
\hline \multirow[t]{7}{*}{12894} & 0 & $4.3(3.0-6.7)$ & $--(--)$ & $4.9(3.7-6.0)$ & $3.5(2.8-4.6)$ \\
\hline & 30 & $8.1(4.6-29.7)$ & $--(--)$ & $19.7(9.0-34.3)$ & $3.7(3.6-4.4)$ \\
\hline & 60 & $4.9(3.7-15.6)$ & $--(--)$ & $8.9(4.9-31.4)$ & $3.0(2.5-4.2)$ \\
\hline & 90 & $5.8(3.5-47.0)$ & $--(--)$ & $17.6(8.7-50.5)$ & $--(--)$ \\
\hline & 120 & $4.4(3.1-8.1)$ & $--(--)$ & $6.4(3.6-26.7)$ & $3.1(2.6-4.1)$ \\
\hline & 150 & $3.4(2.9-5.0)$ & $3.1(2.5-4.3)$ & $4.4(3.0-5.9)$ & $2.8(2.2-3.5)$ \\
\hline & 180 & $3.5(2.4-5.7)$ & $3.2(--)$ & $4.1(2.7-6.8)$ & $2.8(1.9-3.0)$ \\
\hline \multirow[t]{5}{*}{15327} & 0 & $1.5(1.3-2.4)$ & $1.6(1.5-2.0)$ & $1.6(1.4-2.2)$ & $1.8(1.5-2.5)$ \\
\hline & 30 & $1.8(1.5-5.1)$ & $1.6(1.4-2.3)$ & $2.1(1.6-5.9)$ & $1.5(1.3-1.7)$ \\
\hline & 90 & $1.5(1.3-2.4)$ & $1.6(1.5-2.0)$ & $1.6(1.4-2.2)$ & $1.8(1.5-2.5)$ \\
\hline & 150 & $2.2(1.8-2.8)$ & $1.9(1.7-2.2)$ & $2.3(1.4-6.9)$ & $1.8(1.5-2.2)$ \\
\hline & 180 & $1.8(1.5-5.1)$ & $1.6(1.4-2.3)$ & $2.1(1.6-5.9)$ & $1.5(1.3-1.7)$ \\
\hline \multirow[t]{5}{*}{88} & 0 & $147.4(32.2-335.0)$ & $--(--)$ & $202.9(61.2-493.8)$ & $2.2(--)$ \\
\hline & 30 & 47.7 (35.1-120.6) & 9.7 (5.8-21.1) & 601.8 (89.4-1693.6) & $27.0(--)$ \\
\hline & 90 & $105.6(51.2-141.0)$ & $13.3(8.4-22.7)$ & $245.9(116.8-529.2)$ & $16.4(14.3-24.1)$ \\
\hline & 150 & 83.2 (47.9-323.3) & $7.8(4.7-14.5)$ & $562.3(388.3-625.3)$ & $10.9(--)$ \\
\hline & 180 & $194.2(53.1-311.6)$ & $14.6(8.5-21.2)$ & 388.9 (157.5-763.6) & $21.8(18.6-281.4)$ \\
\hline \multirow[t]{7}{*}{90} & 0 & $7.8(--)$ & $17.5(--)$ & $33.2(28.5-51.4)$ & $--(--)$ \\
\hline & 30 & 36.5 (33.4-46.8) & $9.2(--)$ & 50.6 (34.8-105.8) & $14.2(--)$ \\
\hline & 60 & $11.8(8.4-22.8)$ & $10.2(3.0-14.7)$ & $41.3(16.6-75.2)$ & $--(--)$ \\
\hline & 90 & $11.1(--)$ & $--(--)$ & -- (--) & $--(--)$ \\
\hline & 120 & $50.6(46.8-85.5)$ & $12.8(--)$ & 94.8 (49.3-155.6) & $--(--)$ \\
\hline & 150 & $36.0(26.0-54.7)$ & $41.7(--)$ & 64.6 (47.2-116.9) & $8.1(--)$ \\
\hline & 180 & $9.2(4.2-16.0)$ & $2.7(--)$ & $5.4(2.3-25.2)$ & $3.6(--)$ \\
\hline
\end{tabular}




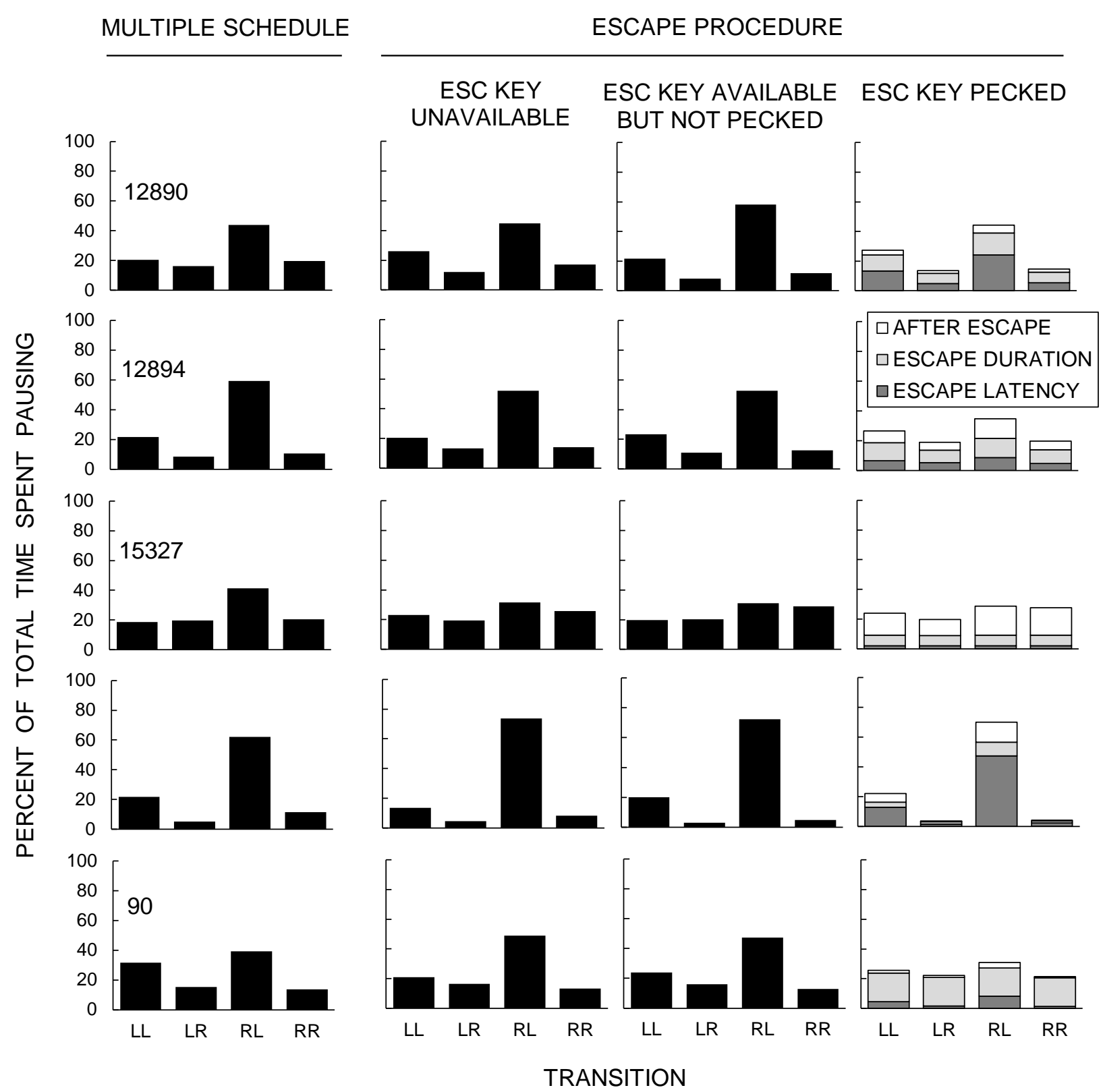

Figure 7. Experiment 2. Percent of total spent time pausing during the lean-lean (LL), lean-rich (LR), rich-lean (RL), and rich-rich (RR) transitions during the multiple-schedule training (column 1) and during the escape procedure (columns 2-4). All results are collapsed across the line tilt conditions. The percentages during the escape procedure are shown separately for when no escape key was available (column 2), the escape key was available but was not pecked (column 3), and the escape key was pecked (column 4). Column 4 shows the latencies to peck the escape key, escape durations, and post-escape pauses. All are expressed as the percent of total time spent pausing in each transition. 
pauses and interquartile ranges are shown in Appendix F. Overall, pausing was the longest during rich-lean transitions followed by intermediate pauses in the lean-lean transitions and short pauses in the lean-rich and rich-rich transitions. These results show that pausing was under the control of the nature of the transition.

Columns 2 and 3 of Figure 7 show relative pausing, collapsed across line tilts, for each transition during the escape procedure. Appendix G provides the absolute values of the median pauses and interquartile ranges for all individual line-tilt conditions. Pausing is calculated separately for when no escape key was available (column 2) and when the escape key was available but was not pecked (column 3). Overall, pausing during the escape procedure remained under the control of the nature of the transitions for all pigeons throughout the escape procedure. Pausing was the longest during rich-lean transitions followed by intermediate pauses in the leanlean transitions and short pauses in the lean-rich and rich-rich transitions. This pattern was shown regardless of the availability of the escape key and regardless of whether the pigeons pecked the escape key.

Column 4 in Figure 7 shows a more extensive analysis of pausing during each transition when the escape key was pecked. In this analysis, pausing is defined as the time from the start of the component until the fifth peck on the food key. In situations in which the escape key was pecked, pausing can be broken down into three parts: the latencies to peck the escape key, the escape durations, and the time between the end of escape and fifth peck on the food key (i.e., post-escape pauses). Column 4 in Figure 7 shows the duration of the three measures in each of the four transitions relative to the total time spent pausing (i.e., the percentages). Table 8, Appendix E, and Appendix H provide the absolute values of the medians and interquartile ranges for all three measures in all individual line-tilt conditions. 
Overall, there was considerable variability across pigeons regarding the relative latencies to peck the escape key, escape durations, and post-escape pauses. While the latencies for two pigeons (12890 and 88) were relatively long, the latencies for the other three pigeons (12894, 15327, and 90) were short. While the escape duration for four pigeons (12890, 12894, 15327, and 88) was relatively short, one pigeon (90) rarely pecked to leave the escape period and therefore, the escape durations were long. When the escape periods were ended, the post-escape pauses were relatively short for four pigeons $(12890,12984,88$, and 90$)$, indicating that these pigeons resumed pecking the food key relatively quickly. The post-escape pauses were relatively long for the fifth pigeon (15327), indicating that this pigeon took longer to resume pecking the food key. For most cases, the latencies to peck the escape key, escape durations, and post-escape pauses were relatively longer in the rich-lean transitions than any other transition.

\section{Discussion}

Experiment 2 sought to extend the investigation of the aversive functions of stimuli correlated with rich and lean schedules of reinforcement in an escape procedure. The goal was to assess the effects of the magnitude of the stimulus change that occurs when an escape response removes stimuli correlated with rich and lean schedules. The present experiment manipulated the magnitude of stimulus change by systematically altering the physical appearance of the escape key stimulus after an escape response.

The present experiment provided evidence that stimuli correlated with lean schedules of reinforcement are aversive. Overall, escape occurred the most in the rich-lean transitions and the second-most in the lean-lean transitions. For most pigeons, escape was infrequent in the lean-rich and rich-rich transitions. In addition, parallels between pausing and escape responding were shown for most of the pigeons. All pigeons showed extended pauses in the rich-lean transitions 
throughout the experiment, regardless of whether an escape key was available or an escape response occurred. The finding that the longest pauses and the highest probabilities of escape both occurred in the rich-lean transitions is consistent with previous studies of escape responding on multiple schedules (Carlin, 1998; Everly et al., 2014; Perone, 2003; Retzlaff et al., 2017).

Overall, the magnitude of stimulus change produced by changing the tilt of the line on the escape key did not reliably affect the probability of escape systematically. Only for one pigeon (12894) was the probability of escape directly related to the magnitude of change. These results are inconsistent with Zimmerman and Ferster’s (1964) study, which showed that escape responding on simple FR schedules was related to the magnitude of stimulus change. To reconcile these differences, the following discussion will analyze the methods used in each study to generate the stimulus changes.

One consistency between the present results and Zimmerman and Ferster’s (1964) results is the relevance of the houselight. In the initial escape procedure of the present experiment, the houselight remained on during the escape periods to minimize additional stimulus changes in the chamber other than the changes in the line tilt. By not changing the state of the houselight throughout the session, the present experiment departed not only from Zimmerman and Ferster's experiment, but also from all other escape procedures that suspended the schedule of reinforcement following an escape response (Azrin, 1961; Carlin, 1998; Cohen \& Campagnoni, 1989; Perone, 2003; Retzlaff et al., 2017, Experiment 2). Escape responding in the present experiment was not maintained when the houselight remained on during the escape period. When the procedure was modified so that the escape response resulted in the offset of the houselight along with the change in the line tilt, escape became more probable for all of the pigeons. 
This result indicates that a large stimulus change, per se, may be a necessary component of procedures used to generate escape. One potential limitation to this notion is that a large stimulus change is not a necessary component to generate escape in procedures that do not suspend the schedule, such as in the escape experiments conducted by Everly et al. (2014) and Retzlaff et al. (2017, Experiment 1). In their procedures, the escape response darkened the escape key and changed the color on the food key from the color correlated with the rich or lean schedule to a neutral color (i.e., mixed stimulus). The houselight was not turned off and the FR schedule was not suspended. Despite this, the pigeons still pecked the escape key. It is possible that in these experiments, the escape response actually produced two functional consequences. First, the escape response removed the stimulus correlated with the schedule, which would indicate that the stimulus was aversive. Second, the escape response produced the mixed stimulus, which would indicate that the mixed stimulus was reinforcing - at least during the components in which the stimuli correlated with the schedule are aversive. Therefore, both of these consequences may have influenced escape responding in these experiments. If this is the case, then the added reinforcing function of the mixed stimulus could account for the fact that a large stimulus change was an unnecessary procedure to generate escape in these experiments. In the present experiment, the pigeons were unable to produce a mixed stimulus and therefore receive two reinforcing consequences after an escape response. Thus, it is still possible that a large stimulus change is a necessary part of escape procedures that suspend the schedule.

It is notable that large stimulus changes during escape do not need to occur by turning chamber stimuli off. One might expect that turning off the houselight would be an especially salient stimulus, because the houselight is always turned off before the session starts and after it ends. That is, the animal has had a lot of experience with the discrimination between when the 
schedule is in effect and when it is not. However, Cohen and Campgnoni (1989) changed the stimulus conditions when the pigeons retreated to the rear of the chamber by lighting five additional houselights. In addition, for some of the pigeons in Azrin's (1961) experiment, the escape response increased the brightness and changed the color of the houselight. In both of these studies, the escape response changed the stimulus conditions by making the chamber brighter.

It may be important to consider why changes in stimuli other than those on the food and escape keys play a role in maintaining escape. Even though the houselight is always on when the schedule is in effect, there is reason to believe that its presence can become aversive because of the correlation between the reinforcer ending and its onset. If this is the case, then the removal of the houselight, which is part of entire aversive context, is likely to be reinforcing.

One potentially relevant feature of the houselight is its diffuse nature. Typically, chamber lighting is produced by the houselight and the lit response keys. Because lit response keys produce low levels of illumination in the chamber, it may be easy for the pigeons to reduce contact with them by simply turning around and moving to the back of the chamber. Illumination provided by the houselight, however, is diffused throughout the entire chamber. It may be that pigeons are more likely to peck an escape key to alter this diffuse stimulus when it becomes aversive after the delivery of a reinforcer because they cannot easily reduce contact with it by simply turning around in the chamber.

This interpretation may help to explain why the alterations in the magnitude of the stimulus change in the present experiment failed to control escape responding for the majority of the pigeons. The only change made to the stimulus conditions in the chamber across conditions was the tilt of the $90^{\circ}$ line on the escape key following an escape response. When an escape 
response occurred, the line on the escape key was tilted from $90^{\circ}$ to either $0^{\circ}, 30^{\circ}, 60^{\circ}, 120^{\circ}$, $150^{\circ}, 180^{\circ}$, or not at all (i.e., the line remained at $90^{\circ}$ ). Therefore, each line tilt constituted a different magnitude of stimulus change from the $90^{\circ}$ line. Because there were no reliable effects of the line tilts on escape responding, it seems likely that the stimulus change produced by merely tilting the line was not large enough to exert differential effects on escape responding.

Another possible reason for the unsystematic effects of the line tilts is that these pigeons were not under the control of the relevant stimulus dimensions of the line tilt stimuli. For example, consider the visual difference between the $0^{\circ}$ and $90^{\circ}$ line tilt stimuli shown in Table 6 . The major difference between these two stimuli lies in the location of the white and black parts of the image. On some parts of the key, such as the very center or the upper righthand sections of the keys, there are no differences between the two stimuli. In contrast, other parts of the key, such as the topmost or rightmost parts of the two keys, are starkly different. The possibility that individual pigeons do not attend to the entirety of the stimuli presented on the key and instead only attend to specific sections of the key leaves open potential limitations in control by the line tilts. The notion that relevant dimensions of complex visual stimuli are obscure and that the scaling of complex stimuli in terms of rotation does not always produce orderly results has been shown in the literature on stimulus generalization and discrimination (Dinsmoor, 1985; Reynolds, 1961; Vetter \& Hearst, 1968). Therefore, it is possible that these pigeons were sensitive to stimulus changes, but the nature of the degree of each stimulus change attended to by each pigeon may not have corresponded to the programmed stimulus changes.

In light of the present results, future research on escape responding might consider altering the method used to present stimulus changes. For example, instead of using line tilts to systematically alter the degree of stimulus change, the level of illumination provided by the 
houselight could be altered. It is likely that only a slight dimming of the houselight when an escape response occurs would be less reinforcing than turning the houselight off. Then, gradations in between these illuminance levels could be investigated. Alternatively, the degree of stimulus change could still be altered on the escape key, as in the present experiment. However, variations in less complex stimuli, such as colors, could be used instead of line tilts to eliminate the possibility that pigeons could attend to different aspects of the stimuli.

\section{Conclusions}

The present experiments assessed the behavioral function of rich and lean stimuli in observing and escape procedures. The potential aversive function of lean stimuli was the primary focus. In Experiment 1, the lean stimuli were not aversive enough to punish observing. In Experiment 2, the lean stimuli were aversive enough to maintain escape from rich-lean transitions. These contrasting results indicate that either the aversive functions of stimuli correlated with lean schedules are dependent on the overall procedural context or that the procedures used to measure aversive functions are differentially sensitive at detecting them.

In line with present research (e.g., Perone \& Courtney, 1992) all pigeons in the present experiments showed extended pauses when the rich-lean transitions were discriminable, regardless of whether an escape or observing procedure was underway. Despite the similarity of pausing in both of the present experiments, the two experiments obtained opposite findings in regards to whether the lean stimuli are aversive. As described above, it is possible that the observing procedure used in Experiment 1, which did not produce evidence that the lean stimuli were aversive, was not a sensitive enough test of aversiveness. In contrast, the escape procedure used in Experiment 2 was sensitive. Apart from the general flaws of the particular observing procedure in the present study, some authors (Azrin et al., 1965; Dinsmoor, 1985; Everly et al., 
2014; Perone, 2003) have contended that procedures designed to punish responding, such as in the observing experiment, are not always as sensitive at detecting aversive functions as procedures designed to reinforce avoidance or escape responding, such as in the escape experiment. For example, Azrin et. al. (1965) used both positive punishment procedures and escape procedures to evaluate the aversive functions of electric shock. In the punishment procedure, pigeons' key pecks were maintained by food reinforcement and across conditions, electric shock was presented at differing intensities following each key peck. The shocks produced only minimal reductions in responding at shock intensities below $60 \mathrm{v}$. In the escape procedure, the same pigeons could peck an escape key to remove the punishment contingency and therefore, remove the possibility of receiving shocks. Interestingly, the pigeons escaped at intensities as low as $20 \mathrm{v}$, despite the fact that this low intensity failed to produce punishing effects. These results show that the same stimulus (e.g., 20-v shock) is not always aversive under different procedures. This explanation may account for the differences in detecting aversive functions of the lean stimuli in the present experiments.

The procedural changes made to the escape and observing procedures in the present experiments did not appear to enhance these procedures. In the observing experiment, the use of transition-specific stimuli showed no evidence of enhanced stimulus control or aversive functions when compared to Everly et al.’s (2014) experiment that did not use transition-specific stimuli. In the escape experiment, the results of the two pigeons (88 and 90) that were exposed to the transition-specific stimuli were not different from the results from the pigeons who were not exposed to transition-specific stimuli. Furthermore, using systematic changes in line tilts in the escape experiment as the method of delivering stimulus changes did not differentially control escape responding for the majority of the pigeons. 
Nevertheless, the overall findings show that lean stimuli can be aversive and can generate behavior that permits an individual to remove them. These findings may be important in understanding problematic behavior in clinical settings. Previous research has found that problematic behavior for individuals with intellectual and developmental disabilities often occurs during transitions between different activities (for a review, see Brewer et al., 2014; Luczynski \& Rodriguez, 2015). It is possible that the problematic behavior is occurring when the schedules of reinforcement in the individual's environment shift from being relatively rich to relatively lean during the activity transitions. It may be useful for clinicians to analyze the nature of the transitions and take steps to minimize any aversive aspects. 


\section{References}

Azrin, N. H. (1961). Time-out from positive reinforcement. Science, 133(3450), 382-383.

Azrin, N. H., Hake, D. F., Holz, W. C., \& Hutchinson, R. R. (1965). Motivational aspects of escape from punishment. Journal of the Experimental Analysis of Behavior, 8(1), 31-44.

Baron, A., \& Herpolsheimer, L. R. (1999). Averaging effects in the study of fixed-ratio response patterns. Journal of the Experimental Analysis of Behavior, 71(2), 145-153.

Baron, A., Mikorski, J., \& Schlund, M. (1992). Reinforcement magnitude and pausing on progressive-ratio schedules. Journal of the Experimental Analysis of Behavior, 58(2), 377-388.

Brewer, A., Johnson, P., Stein, J., Schlund, M., \& Williams, D. C. (2017). Aversive properties of negative incentive shifts in Fischer 344 and Lewis rats. Behavioural Brain Research, 319, 174-180.

Carlin, L. A. (1998). Pausing and escape on fixed-interval schedules: Effects of stimuli correlated with different reinforcer magnitudes and different reinforcement rates (Doctoral dissertation, West Virginia University Libraries).

Case, D. A., \& Fantino, E. (1981). The delay-reduction hypothesis of conditioned reinforcement and punishment: Observing behavior. Journal of the Experimental Analysis of Behavior, 35(1), 93-108.

Cohen, P. S., \& Campagnoni, F. R. (1989). The nature and determinants of spatial retreat in the pigeon between periodic grain presentations. Animal Learning \& Behavior, 17(1), 39-48.

Dinsmoor, J. A. (1985). The role of observing and attention in establishing stimulus control. Journal of the Experimental Analysis of Behavior, 43(3), 365-381. 
Everly, J. B., Holtyn, A. F., \& Perone, M. (2014). Behavioral functions of stimuli signaling transitions across rich and lean schedules of reinforcement. Journal of the Experimental Analysis of Behavior, 101(2), 201-214.

Ferster, C. B., \& Skinner, B. F. (1957). Schedules of reinforcement. New York: AppletonCentury-Crofts.

Galuska, C. M., Wade-Galuska, T., Woods, J. H., \& Winger, G. (2007). Fixed-ratio schedules of cocaine self-administration in rhesus monkeys: Joint control of responding by past and upcoming doses. Behavioral Pharmacology, 18, 229-235.

Galuska, C. M., \& Yadon, K. A. (2011). The effect of prefeeding on fixed-ratio pausing is jointly determined by past and upcoming reinforcer magnitudes. Behavioural Processes, 86(1), 156-159.

Hanley, G. P., Iwata, B. A., \& McCord, B. E. (2003). Functional analysis of problem behavior: A review. Journal of Applied Behavior Analysis, 36(2), 147-185.

Harris, A., Foster, T. M., Levine, J., \& Temple, W. (2012). Effects of a signaled delay to reinforcement in the previous and upcoming ratios on between-ratio pausing in fixedratio schedules. Journal of the Experimental Analysis of Behavior, 98(3), 295-309.

Jwaideh, A. R., \& Mulvaney, D. E. (1976). Punishment of observing by a stimulus associated with the lower of two reinforcement frequencies. Learning and Motivation, 7(2), 211222.

Kish, G. B. (1955). Learning when the onset of illumination is used as the reinforcing stimulus. Journal of Comparative and Physiological Psychology, 48(4), 261.

Kish, G. (1966). Studies of sensory reinforcement. Operant behavior: Areas of research and application, 109-159. 
Langford, J. S., Pitts, R. C., \& Hughes, C. E. (2019). Assessing functions of stimuli associated with rich-to-lean transitions using a choice procedure. Journal of the Experimental Analysis of Behavior, 112(1), 97-110.

Luczynski, K. C., \& Rodriguez, N. M. (2015). Assessment and treatment of problem behavior associated with transitions. In Autism Service Delivery (pp. 151-173). Springer, New York, NY.

Mazur, J. E. (1983). Steady-state performance on fixed-, mixed-, and random-ratio schedules. Journal of the Experimental Analysis of Behavior, 39(2), 293-307.

Perone, M. (2003). Negative effects of positive reinforcement. The Behavior Analyst, 26(1), 114.

Perone, M., \& Courtney, K. (1992). Fixed-ratio pausing: Joint effects of past reinforcer magnitude and stimuli correlated with upcoming magnitude. Journal of the Experimental Analysis of Behavior, 57(1), 33-46.

Retzlaff, B. J., Parthum, E. T., Pitts, R. C., \& Hughes, C. E. (2017). Escape from rich-to-lean transitions: Stimulus change and timeout. Journal of the Experimental Analysis of Behavior, 107(1), 65-84.

Reynolds, G. S. (1961). Attention in the Pigeon. Journal of the Experimental Analysis of Behavior, 4(3), 203-208.

Sawyer, L. E., Galuska, C. M., Cutright, E. J., \& Hopper, K. M. (2019). Effects of negative incentive shifts in food reward on rats' consumption of concurrent ethanol solutions. Journal of the Experimental Analysis of Behavior, 112(3), 310-333.

Schlinger, H. D., Derenne, A., \& Baron, A. (2008). What 50 years of research tell us about pausing under ratio schedules of reinforcement. The Behavior Analyst, 31(1), 39-60. 
Toegel, F. J. (2017). Disruptions in Operant Behavior of Pigeons in Transitions across Rich and Lean Schedules of Reinforcement With and Without Advance Notice of the Lean Schedule. West Virginia University.

Wade-Galuska, T., Perone, M., \& Wirth, O. (2005). Effects of past and upcoming response-force requirements on fixed-ratio pausing. Behavioural Processes, 68(1), 91-95.

Williams, D. C., Saunders, K. J., \& Perone, M. (2011). Extended pausing by humans on multiple fixed-ratio schedules with varied reinforcer magnitude and response requirements. Journal of the Experimental Analysis of Behavior, 95(2), 203-220.

Vetter, G. H., \& Hearst, E. (1968). Generalization and discrimination of shape orientation in the pigeon. Journal of the Experimental Analysis of Behavior, 11(6), 753-765.

Young, R., Foster, T. M., \& Bizo, L. A. (2017). The effects of reinforcer magnitude in the preceding and upcoming ratios on between-ratio pausing in multiple, mixed, and single fixed-ratio schedules. Journal of the Experimental Analysis of Behavior, 108(3), 414-432.

Zimmerman, J., \& Ferster, C. B. (1964). Some notes on time out from reinforcement. Journal of the Experimental Analysis of Behavior, 7(1), 13-19. 


\section{Appendix A}

Experiment 1. Median pauses (s) and interquartile ranges for each transition type in the stable sessions of the multiple schedule training.

\begin{tabular}{ccccc}
\hline & \multicolumn{4}{c}{ Transition Type } \\
\cline { 2 - 5 } Pigeon & Lean-Lean & Lean-Rich & Rich-Lean & Rich-Rich \\
\hline 12749 & $3.8(3.4-4.4)$ & $3.0(2.7-3.4)$ & $9.9(7.2-13.1)$ & $4.6(4.0-5.5)$ \\
12777 & $17.9(11.7-25.3)$ & $3.6(3.1-4.3)$ & $95.2(47.9-152.9)$ & $8.2(6.8-9.7)$ \\
9202 & $87.0(25.9-382.7)$ & $14.7(11.4-18.1)$ & $807.6(120.9-1488.1)$ & $16.1(13.4-19.2)$ \\
15390 & $10.4(7.3-15.6)$ & $5.7(4.7-6.5)$ & $31.8(17.8-59.9)$ & $8.7(7.9-10.3)$ \\
\hline
\end{tabular}




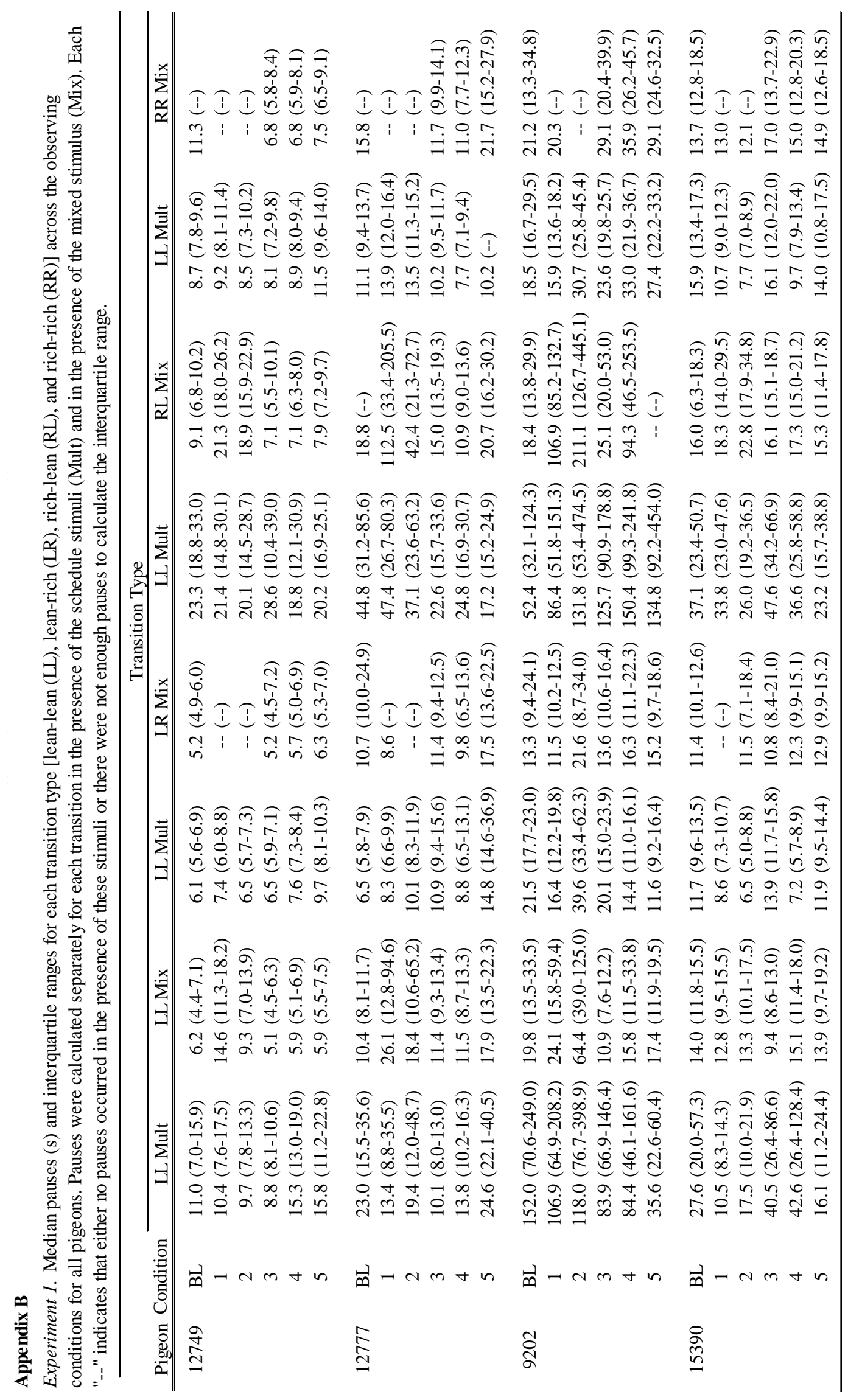




\section{Appendix C}

Experiment 2. Percentage of transitions of each type completed by the three pigeons that did not complete all sessions of each condition. Percentages for each transition type were calculated separately for the transitions in which the escape key was available (No Escape) and transitions in which the escape key was available (Escape). Conditions are listed in the order in which they were completed.

\begin{tabular}{|c|c|c|c|c|c|c|c|c|c|}
\hline \multirow[b]{3}{*}{ Pigeon } & \multirow[b]{3}{*}{$\begin{array}{l}\text { Line } \\
\text { Tilt } \\
\end{array}$} & \multicolumn{8}{|c|}{ Transition Type } \\
\hline & & \multicolumn{2}{|c|}{ Lean-Lean } & \multicolumn{2}{|c|}{ Lean-Rich } & \multicolumn{2}{|c|}{ Rich-Lean } & \multicolumn{2}{|c|}{ Rich-Rich } \\
\hline & & $\begin{array}{c}\text { No Escape } \\
\text { Key }\end{array}$ & $\begin{array}{c}\text { Escape } \\
\text { Key }\end{array}$ & $\begin{array}{c}\text { No Escape } \\
\text { Key }\end{array}$ & $\begin{array}{c}\text { Escape } \\
\text { Key }\end{array}$ & $\begin{array}{c}\text { No Escape } \\
\text { Key }\end{array}$ & $\begin{array}{c}\text { Escape } \\
\text { Key }\end{array}$ & $\begin{array}{c}\text { No Escape } \\
\text { Key }\end{array}$ & $\begin{array}{c}\text { Escape } \\
\text { Key }\end{array}$ \\
\hline \multirow[t]{5}{*}{12890} & 0 & 82 & 86 & 84 & 86 & 82 & 84 & 90 & 86 \\
\hline & 90 & 100 & 100 & 100 & 100 & 100 & 100 & 100 & 100 \\
\hline & 180 & 100 & 100 & 100 & 100 & 100 & 100 & 100 & 100 \\
\hline & 30 & 100 & 100 & 100 & 100 & 100 & 100 & 100 & 100 \\
\hline & 150 & 100 & 100 & 100 & 100 & 100 & 100 & 100 & 100 \\
\hline \multirow[t]{5}{*}{15327} & 0 & 100 & 100 & 100 & 100 & 100 & 100 & 100 & 100 \\
\hline & 90 & 92 & 96 & 100 & 98 & 100 & 98 & 98 & 96 \\
\hline & 180 & 76 & 78 & 80 & 82 & 76 & 80 & 78 & 82 \\
\hline & 30 & 70 & 62 & 80 & 76 & 80 & 68 & 78 & 78 \\
\hline & 150 & 38 & 54 & 38 & 46 & 38 & 40 & 50 & 42 \\
\hline \multirow[t]{5}{*}{88} & 0 & 100 & 100 & 100 & 100 & 100 & 100 & 100 & 100 \\
\hline & 90 & 96 & 96 & 100 & 96 & 96 & 98 & 94 & 94 \\
\hline & 180 & 82 & 78 & 86 & 94 & 94 & 82 & 92 & 94 \\
\hline & 30 & 88 & 94 & 98 & 92 & 94 & 94 & 96 & 96 \\
\hline & 150 & 96 & 96 & 100 & 96 & 98 & 96 & 98 & 96 \\
\hline
\end{tabular}




\section{Appendix D}

Experiment 2. Total time spent in escape, in seconds, for each transition type in the stable sessions for each condition. Each value represents the sum of all escape durations that occurred in the 10 stable sessions of each condition.

\begin{tabular}{|c|c|c|c|c|c|}
\hline \multirow[b]{2}{*}{ Pigeon } & \multirow[b]{2}{*}{ Line Tilt } & \multicolumn{4}{|c|}{ Transition Type } \\
\hline & & Lean-Lean & Lean-Rich & Rich-Lean & Rich-Rich \\
\hline \multirow[t]{5}{*}{12890} & 0 & 953 & 26 & 1316 & 72 \\
\hline & 30 & 34 & 0 & 69 & 51 \\
\hline & 90 & 376 & 120 & 895 & 6 \\
\hline & 150 & 13 & 7 & 9 & 0 \\
\hline & 180 & 630 & 133 & 957 & 196 \\
\hline \multirow[t]{7}{*}{12894} & 0 & 355 & 0 & 350 & 54 \\
\hline & 30 & 390 & 0 & 555 & 18 \\
\hline & 60 & 164 & 0 & 254 & 32 \\
\hline & 90 & 109 & 0 & 170 & 0 \\
\hline & 120 & 368 & 0 & 360 & 111 \\
\hline & 150 & 474 & 92 & 482 & 198 \\
\hline & 180 & 235 & 5 & 301 & 61 \\
\hline \multirow[t]{5}{*}{15327} & 0 & 471 & 815 & 599 & 848 \\
\hline & 30 & 225 & 245 & 622 & 486 \\
\hline & 90 & 472 & 354 & 419 & 364 \\
\hline & 150 & 182 & 176 & 351 & 219 \\
\hline & 180 & 578 & 197 & 622 & 1265 \\
\hline \multirow[t]{5}{*}{88} & 0 & 583 & 0 & 748 & 31 \\
\hline & 30 & 319 & 286 & 1546 & 25 \\
\hline & 90 & 1089 & 168 & 2014 & 23 \\
\hline & 150 & 417 & 73 & 891 & 10 \\
\hline & 180 & 1542 & 80 & 2615 & 51 \\
\hline \multirow[t]{7}{*}{90} & 0 & 120 & 120 & 1206 & 0 \\
\hline & 30 & 600 & 120 & 1080 & 240 \\
\hline & 60 & 393 & 149 & 1467 & 0 \\
\hline & 90 & 120 & 0 & 0 & 0 \\
\hline & 120 & 480 & 120 & 1440 & 0 \\
\hline & 150 & 720 & 120 & 1200 & 120 \\
\hline & 180 & 480 & 240 & 840 & 240 \\
\hline
\end{tabular}




\section{Appendix E}

Experiment 2. Median escape duration (s) and interquartile ranges for each transition type in the stable sessions for each condition. Each "--" indicates that either no escape responding occurred or there were not enough escape responses to calculate the interquartile range.

\begin{tabular}{|c|c|c|c|c|c|}
\hline \multirow[b]{2}{*}{ Pigeon } & \multirow[b]{2}{*}{ Line Tilt } & \multicolumn{4}{|c|}{ Transition Type } \\
\hline & & Lean-Lean & Lean-Rich & Rich-Lean & Rich-Rich \\
\hline \multirow[t]{5}{*}{12890} & 0 & $14.8(5.9-73.9)$ & 8.7 (5.3-11.7) & $24.5(6.3-120.0)$ & $8.5(6.5-18.2)$ \\
\hline & 30 & $6.3(6.2-21.7)$ & $--(--)$ & $11.4(9.9-13.0)$ & $13.1(12.3-25.2)$ \\
\hline & 90 & 85.7 (25.1-120.0) & $120.0(--)$ & $120.0(21.6-120.0)$ & $6.3(--)$ \\
\hline & 150 & $13.5(--)$ & $7.4(--)$ & $8.8(--)$ & $--(--)$ \\
\hline & 180 & $25.3(8.7-60.6)$ & $16.4(8.0-32.8)$ & $42.3(13.0-120.0)$ & $12.0(8.3-83.6)$ \\
\hline \multirow[t]{7}{*}{12894} & 0 & $6.6(5.8-10.2)$ & $--(--)$ & $8.2(6.0-10.5)$ & $8.7(6.5-11.8)$ \\
\hline & 30 & $13.1(7.8-23.9)$ & $--(--)$ & $9.8(6.8-19.0)$ & $6.0(5.2-7.3)$ \\
\hline & 60 & $8.4(5.8-16.5)$ & $--(--)$ & $12.4(7.4-16.2)$ & $6.8(5.2-11.9)$ \\
\hline & 90 & $7.7(6.4-14.2)$ & $--(--)$ & $10.2(7.6-15.7)$ & $--(--)$ \\
\hline & 120 & $14.8(6.0-34.7)$ & $--(--)$ & $17.6(5.7-37.0)$ & $5.5(5.1-6.6)$ \\
\hline & 150 & $8.6(6.6-11.8)$ & $5.4(5.2-5.6)$ & $7.7(6.1-10.7)$ & $5.8(5.3-8.0)$ \\
\hline & 180 & $6.1(5.4-7.6)$ & $5.4(--)$ & $6.2(5.3-8.4)$ & $6.5(5.5-7.7)$ \\
\hline \multirow[t]{5}{*}{15327} & 0 & $5.3(5.1-5.5)$ & $5.2(5.1-5.4)$ & $5.2(5.1-5.4)$ & $5.3(5.2-5.8)$ \\
\hline & 30 & $5.2(5.1-6.3)$ & $5.3(5.2-5.6)$ & $5.7(5.2-6.3)$ & $5.5(5.2-7.5)$ \\
\hline & 90 & $5.2(5.1-5.4)$ & $5.1(5.1-5.3)$ & $5.2(5.1-5.4)$ & $5.1(5.1-5.3)$ \\
\hline & 150 & $5.6(5.4-6.0)$ & $5.4(5.1-6.7)$ & $5.4(5.2-5.9)$ & $5.7(5.3-6.2)$ \\
\hline & 180 & $5.3(5.1-14.8)$ & $5.2(5.1-5.5)$ & $5.4(5.2-13.4)$ & $5.8(5.3-120.0)$ \\
\hline \multirow[t]{5}{*}{88} & 0 & 36.3 (28.7-103.2) & $--(--)$ & $48.6(18.7-120.0)$ & $30.8(--)$ \\
\hline & 30 & $12.1(6.6-24.3)$ & $25.5(14.3-38.1)$ & $120.0(19.1-120.0)$ & $12.4(--)$ \\
\hline & 90 & $21.8(6.7-120.0)$ & $10.6(7.0-40.4)$ & 33.5 (14.4-120.0) & $7.2(6.5-9.0)$ \\
\hline & 150 & $37.0(6.9-120.0)$ & $13.2(7.5-22.6)$ & $120.0(26.6-120.0)$ & $10.3(--)$ \\
\hline & 180 & $120.0(10.9-120.0)$ & $11.8(6.8-15.8)$ & $120.0(14.6-120.0)$ & $13.3(7.8-17.5)$ \\
\hline \multirow[t]{7}{*}{90} & 0 & $120.0(--)$ & $120.0(--)$ & $120.0(120.0-120.0$ & $--(--)$ \\
\hline & 30 & $120.0(120.0-120.0$ & $120.0(--)$ & $120.0(120.0-120.0$ & $120.0(--)$ \\
\hline & 60 & $70.1(7.1-120.0)$ & $16.2(12.5-120.0)$ & $120.0(36.2-120.0)$ & -- (--) \\
\hline & 90 & $120.0(--)$ & $--(--)$ & $--(--)$ & $--(--)$ \\
\hline & 120 & $120.0(120.0-120.0$ & $120.0(--)$ & $120.0(120.0-120.0$ & $--(--)$ \\
\hline & 150 & $120.0(120.0-120.0$ & $120.0(--)$ & $120.0(120.0-120.0$ & $120.0(--)$ \\
\hline & 180 & $120.0(120.0-120.0$ & $120.0(--)$ & $120.0(120.0-120.0$ & $120.0(--)$ \\
\hline
\end{tabular}




\section{Appendix F}

Experiment 2. Median pauses (s) and interquartile ranges for each transition type in the stable sessions of the multiple schedule training.

\begin{tabular}{ccccc}
\hline & \multicolumn{4}{c}{ Transition Type } \\
\cline { 2 - 5 } Pigeon & Lean-Lean & Lean-Rich & Rich-Lean & Rich-Rich \\
\hline 12890 & $12.3(9.9-16.8)$ & $9.7(8.1-11.1)$ & $26.3(19.3-39.8)$ & $11.7(10.0-13.0)$ \\
12894 & $10.1(7.7-14.3)$ & $4.1(3.4-4.9)$ & $27.8(21.4-41.4)$ & $5.0(4.3-6.3)$ \\
15327 & $14.0(5.0-34.6)$ & $14.8(5.4-29.9)$ & $31.0(6.2-61.2)$ & $15.4(5.5-36.1)$ \\
88 & $15.6(11.3-21.7)$ & $8.9(7.3-10.4)$ & $44.7(33.2-60.0)$ & $12.5(10.0-15.9)$ \\
90 & $32.8(21.8-53.2)$ & $15.9(12.9-22.9)$ & $40.6(21.4-83.4)$ & $14.2(11.1-18.8)$ \\
\hline
\end{tabular}




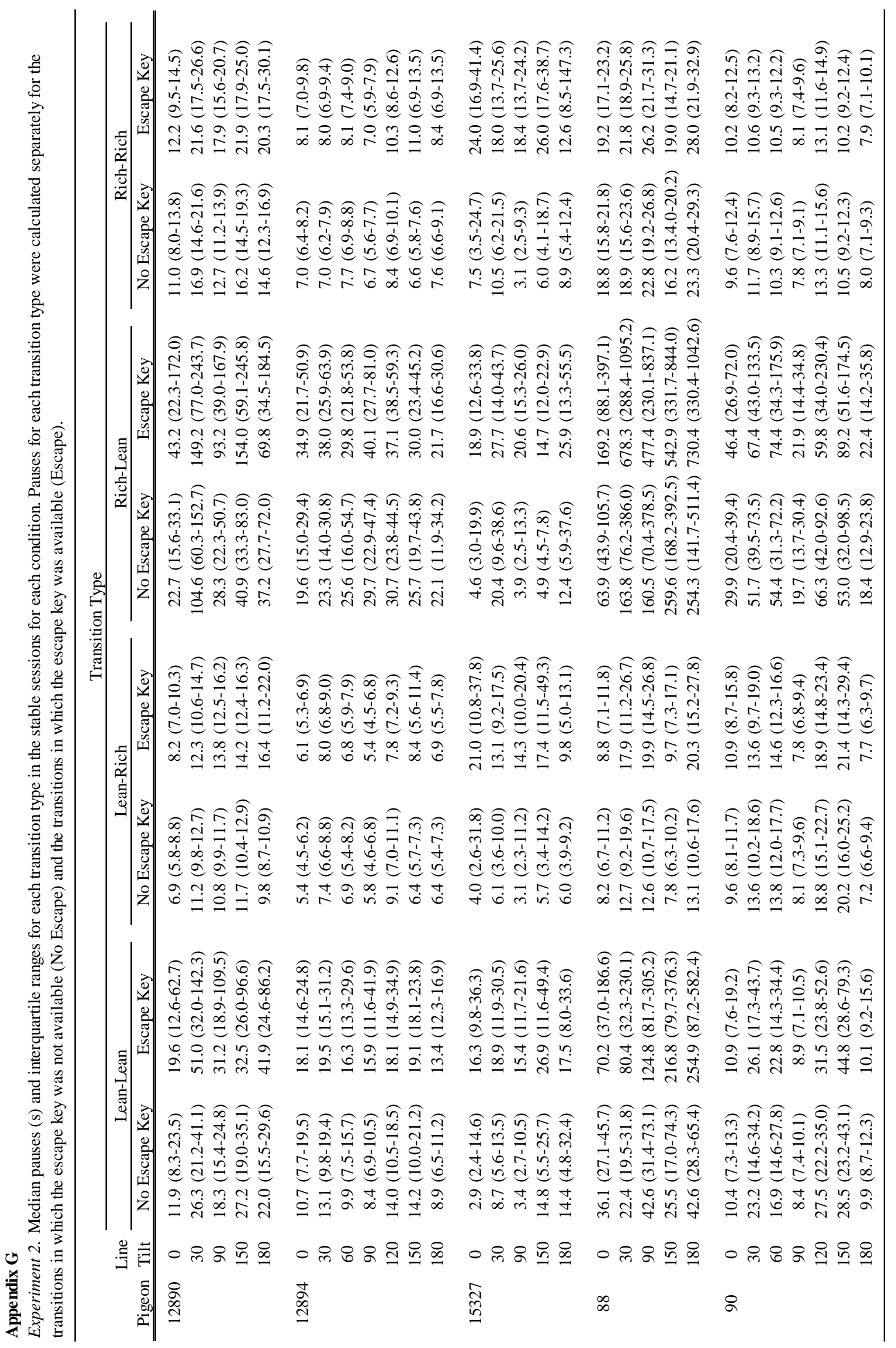




\section{Appendix $\mathbf{H}$}

Experiment 2. Median post-escape pause (s) and interquartile ranges for each transition type in the stable sessions for each condition. Each "--" indicates that either no escape responses occurred or there were not enough escape responses to calculate the interquartile range.

\begin{tabular}{|c|c|c|c|c|c|}
\hline \multirow[b]{2}{*}{ Pigeon } & \multirow[b]{2}{*}{ Line Tilt } & \multicolumn{4}{|c|}{ Transition Type } \\
\hline & & Lean-Lean & Lean-Rich & Rich-Lean & Rich-Rich \\
\hline \multirow[t]{5}{*}{12890} & 0 & $4.9(3.4-10.5)$ & $2.8(2.0-3.1)$ & $6.4(3.8-14.8)$ & $3.8(3.2-4.6)$ \\
\hline & 30 & $5.5(4.8-6.4)$ & $--(--)$ & $9.3(5.0-13.5)$ & $3.8(2.7-4.5)$ \\
\hline & 90 & $17.1(6.7-33.1)$ & $11.0(--)$ & $25.3(5.0-34.5)$ & $2.3(--)$ \\
\hline & 150 & $5.8(--)$ & $3.1(--)$ & $7.4(--)$ & -- (--) \\
\hline & 180 & $6.1(3.8-18.5)$ & $4.0(2.7-4.9)$ & $9.7(5.8-14.2)$ & $4.5(2.9-7.9)$ \\
\hline \multirow[t]{7}{*}{12894} & 0 & $4.1(3.0-8.0)$ & $--(--)$ & $17.5(6.4-28.0)$ & $4.1(3.5-6.2)$ \\
\hline & 30 & $3.9(2.8-8.0)$ & $--(--)$ & $4.6(3.6-7.5)$ & $3.8(2.8-4.7)$ \\
\hline & 60 & $4.5(3.4-10.0)$ & $--(--)$ & $6.1(4.4-12.1)$ & $3.5(3.1-4.7)$ \\
\hline & 90 & $4.8(3.5-6.4)$ & $--(--)$ & $6.0(3.2-11.0)$ & $--(--)$ \\
\hline & 120 & $6.5(4.1-17.5)$ & $--(--)$ & $17.7(8.0-35.5)$ & $3.3(3.0-3.9)$ \\
\hline & 150 & $5.9(4.6-9.6)$ & $3.4(2.6-3.7)$ & $15.4(7.2-24.4)$ & $3.9(3.3-4.3)$ \\
\hline & 180 & $4.1(3.2-5.1)$ & $1.8(--)$ & 7.1 (4.3-12.9) & $3.8(2.9-4.4)$ \\
\hline \multirow[t]{5}{*}{15327} & 0 & $15.0(7.8-39.4)$ & $13.7(6.0-29.6)$ & $16.7(8.2-36.4)$ & $16.1(7.5-33.8)$ \\
\hline & 30 & $10.8(6.3-19.9)$ & $7.2(4.0-10.0)$ & $16.9(6.0-32.6)$ & $12.3(6.8-18.3)$ \\
\hline & 90 & $8.2(5.7-15.1)$ & $8.3(4.2-15.1)$ & $13.5(7.8-18.8)$ & $11.8(6.8-17.7)$ \\
\hline & 150 & $24.0(12.7-43.0)$ & $15.6(5.6-32.8)$ & $6.3(3.9-13.5)$ & $21.8(13.5-51.4)$ \\
\hline & 180 & $7.1(4.8-17.0)$ & $4.6(3.6-7.2)$ & $17.5(13.3-32.3)$ & $9.2(5.8-52.9)$ \\
\hline \multirow[t]{5}{*}{88} & 0 & $35.6(23.4-56.9)$ & $--(--)$ & $38.3(28.8-55.5)$ & $4.6(--)$ \\
\hline & 30 & $7.1(4.4-12.4)$ & $5.6(3.2-7.4)$ & $76.1(20.1-153.7)$ & $15.8(--)$ \\
\hline & 90 & $100.7(49.3-249.8)$ & $4.8(2.3-6.1)$ & $202.6(95.5-454.7)$ & $4.9(0.7-33.0)$ \\
\hline & 150 & $52.5(38.9-153.6)$ & $2.9(1.4-6.0)$ & $68.1(48.9-88.8)$ & $2.6(--)$ \\
\hline & 180 & 71.8 (32.1-445.9) & $4.0(1.8-6.0)$ & $230.1(57.1-419.4)$ & $4.4(1.3-17.6)$ \\
\hline \multirow[t]{7}{*}{90} & 0 & $15.3(--)$ & $6.0(--)$ & $15.8(11.0-31.5)$ & $--(--)$ \\
\hline & 30 & $19.8(12.0-28.1)$ & $3.8(--)$ & $28.6(18.8-71.1)$ & $5.6(--)$ \\
\hline & 60 & $11.6(9.9-15.8)$ & $7.9(7.8-14.5)$ & $29.0(11.4-47.9)$ & $--(--)$ \\
\hline & 90 & $3.1(--)$ & $--(--)$ & $--(--)$ & $--(--)$ \\
\hline & 120 & $11.3(8.3-363.1)$ & $8.4(--)$ & $61.3(23.4-121.5)$ & $--(--)$ \\
\hline & 150 & $13.0(10.3-17.4)$ & $16.2(--)$ & $20.1(6.9-57.0)$ & $4.1(--)$ \\
\hline & 180 & $7.7(7.1-8.1)$ & $8.4(--)$ & $8.1(7.3-15.3)$ & $6.9(--)$ \\
\hline
\end{tabular}

